\title{
EL TURISMO Y EL DESARROLLO SUSTENTABLE DE LAS CIUDADES. EL CASO DE OAXACA, MÉXICO, 2000- 2015
}

\author{
M.A. MARÍA DEL ROSARIO MONCADA GARCÍA ${ }^{1}$ \\ DR. ANDRÉS ENRIQUE MIGUEL-VELASCO ${ }^{2}$ \\ DR. ENRIQUE GUADARRAMA TAVIRA ${ }^{3}$ \\ M.C. KARINA AIDEE MARTÍNEZ GARCÍA ${ }^{4}$ \\ M.C.E. MARIBEL PÉREZ PÉREZ ${ }^{5}$
}

\section{DIVISIÓN DE ESTUDIOS DE POSGRADO E INVESTIGACIÓN TECNOLÓGICO NACIONAL DE MÉXICO / INSTITUTO TECNOLÓGICO DE OAXACA}

\begin{abstract}
Resumen
Partiendo del concepto de turismo como una actividad económica dinámica, capaz de mantener un ritmo de crecimiento favorable, se analiza su influencia en el desarrollo sustentable de las principales ciudades de Oaxaca con una población mayor o cercana a 15 mil habitantes, durante 2000-2015. Se aplica la metodología estadística de la regresión lineal, con el supuesto que el crecimiento del turismo aumenta los niveles de desarrollo sustentable del territorio. El análisis realizado muestra que la relación turismo-desarrollo posee fortalezas y debilidades en las ciudades analizadas. La mayor fortaleza es de carácter sectorial, sobresaliendo el fomento turístico, la capacitación de los recursos humanos y el cuidado ambiental. Territorialmente el turismo manifiesta debilidades para impulsar el mejoramiento del desarrollo sustentable, aunque ya sobresalen las pequeñas ciudades de Oaxaca, lo que debe valorarse debido a que la mayoría de ellas son el lugar central de microrregiones con gran biodiversidad y bioculturalidad. Se recomienda una revisión de las políticas públicas turísticas para hacer más efectivo su impacto territorial.
\end{abstract}

Palabras Clave: Turismo-Ciudades-Oaxaca-Desarrollo sustentable

\footnotetext{
${ }^{1}$ Maestra en Administración- Estudiante del Doctorado en Ciencias en Desarrollo Regional y Tecnológico en el Instituto Tecnológico de Oaxaca, México. Dirección postal: Av. Ing. Victor Bravo Ahuja 125; Oaxaca; México; código postal 68030. Teléfono: 01 9511775717. Correo-e:mogrosario@ hotmail.com

2 Doctor en Ciencias en planificación de empresas y desarrollo regional por el Instituto Tecnológico de Oaxaca, México. Profesor -Investigador de tiempo completo por la División de Estudios de Posgrado e Investigación en el Instituto Tecnológico de Oaxaca. Dirección postal: Av. Ing. Victor Bravo Ahuja 125; Oaxaca, México; código postal 68030. Teléfono: 01951501 5016. Correo-e: andres.miguel@itoaxaca.edu.mx

${ }^{3}$ Doctor en Estudios Turísticos, por la Universidad Autónoma del Estado de México. Profesor -Investigador de tiempo completo de la Facultad de Turismo y Gastronomia. Dirección postal: Cerro de Coatepec s/n, Ciudad Universitaria.

Toluca, Estado de México. CP 50100.Telefono: (722) 2151333 / 214 0220. Correo-e: egtavira@ yahoo.com.mx

${ }^{4}$ Maestra en Ciencias en Desarrollo Regional y Tecnológico- Estudiante del Doctorado en Ciencias en Desarrollo Regional y Tecnológico en el Instituto Tecnológico de Oaxaca, México. Dirección postal: Av. Ing. Victor Bravo Ahuja 125; Oaxaca; México; código postal 68030. Teléfono: 019515015016. Correoe:aide1005@hotmail.com

5 Maestra en Ciencias de la Educación- Estudiante del Doctorado en Ciencias en Desarrollo Regional y Tecnológico en el Instituto Tecnológico de Oaxaca, México. Dirección postal: Av. Ing. Victor Bravo Ahuja 125; Oaxaca; México; código postal 68030. Teléfono: 01951501 5016. Correo-e: mary01758@ hotmail.com
} 


\begin{abstract}
Starting from the concept of tourism as a dynamic economic activity, capable of maintaining a favorable growth rate, its influence on the sustainable development of the main cities of Oaxaca with a population greater than or close to 15 thousand inhabitants during 2000-2015 is analyzed. The statistical methodology of linear regression is applied, with the assumption that tourism growth increases the levels of sustainable development of the territory. The analysis shows that the tourism-development relationship has strengths and weaknesses in the cities analyzed. The greatest strength is of a sectoral nature, with emphasis on tourism development, training of human resources and environmental care. Territorially tourism manifests weaknesses to promote the improvement of sustainable development, although the small cities of Oaxaca stand out, which should be valued because most of them are the central place of microregions with great biodiversity and bioculturality. A review of tourism public policies is recommended to make its territorial impact more effective.
\end{abstract}

Keywords: Tourism-Cities-Oaxaca-Sustainable development.

\title{
1. INTRODUCCIÓN
}

El enfoque teórico actual del turismo considera que, si esta actividad se convierte en un sector económico profesional y productivo, compuesto por empresas innovadoras, competitivas, impulsado por un gobierno facilitador y regulador, promueve la competitividad (Altés, 2006) En las ciudades donde llega a desarrollarse, su importancia económica y para el bienestar incide en la generación de empleos, la atracción de inversiones, el impulso a la economía y sus repercusiones positivas en la calidad de vida de las comunidades a las que impacta, es decir, promueve el desarrollo.

Sin embargo, algunas investigaciones han comprobado que esto no es necesariamente exacto a nivel territorial, pues, por ejemplo, entre más amplio es el espacio en el cual se desenvuelve el turismo, caso de las regiones, menor es su impacto en el desarrollo (Miguel, 2014), por lo cual resulta de interés explorar si el impulso local del turismo, en el caso específico de las localidades y ciudades, incide de mejor manera en el proceso de desarrollo.

En este contexto el presente artículo analiza la influencia del turismo en el desarrollo sustentable de las pequeñas, medianas y grandes ciudades de Oaxaca. Las hipótesis a comprobar son que durante el periodo 2000-2015: 1) la competitividad turística (IT) mantiene una fuerte asociación con el desarrollo sustentable (DS) de la "red de ciudades de Oaxaca" (R $\mathrm{COAX})$; es decir, se espera que a mayor competitividad turística mayor correlación y significancia con el desarrollo sustentable del conjunto de las ciudades analizadas; y 2) que esta asociación manifieste un impacto territorial y no solamente sectorial: a) territorialmente se espera que las ciudades turísticas fundamenten la fortaleza de la relación IT-DS, en tanto que las ciudades no-turísticas contribuyan con el debilitamiento de esta relación; y b) sectorialmente se espera que el factor ambiental fortalezca la relación IT-DS, en tanto que el factor recursos humanos cause el debilitamiento de esta relación en las ciudades de Oaxaca. 


\section{MARCO CONCEPTUAL: EL DESARROLLO SUSTENTABLE Y EL TURISMO EN LAS CIUDADES}

\subsection{La relación de la ciudad y el turismo}

La "ciudad" puede conceptualizarse como una agrupación de personas en un espacio físico continuo, en donde históricamente se han manifestado las realidades sociales, económicas y demográficas, apuntando al componente físico territorial. En 1972 K. Davis definió a la ciudad como una comunidad de tamaño considerable y alta densidad de población con una gran variedad de trabajadores especializados no agrícolas y una elite cultural e intelectual (Sobrino, 2005). Este autor (2005) menciona que las ciudades son localidades con una población de al menos 15 mil habitantes. El INEGI sugiere como indicadores: 1) población rural: la que habita en localidades menores 5 mil habitantes; 2) población semirural: la que vive en localidades de 5 mil a 15 mil habitantes; y 3) población urbana: la población que vive en localidades mayores de 15 mil habitantes, que es el rango donde mayoritariamente se ubican las ciudades analizadas.

Por su parte, la "ciudad sustentable" es aquella que sin violentar los ciclos naturales de su región proveedora, asegura los procesos de consumo y productivos de la sociedad que aloja, tanto en su consumo directo como en las transferencias e intercambios de recursos por desarrollos tecnológicos, y bienes de capital y de consumo duradero en el tiempo y en el espacio. (SEMARNAT, 2016)

Al estar ligada la expansión de las ciudades al proceso de adecuación y ordenamiento territorial de sus aspectos físicos, económicos y ambientales orientados al cambio cuantitativo y cualitativo de las condiciones de vida de la población, las transformaciones que en ella ocurran repercutirán en este proceso. En el contexto de la urbanización, el desarrollo territorial no es un proceso aislado, más bien es resultado de la interacción existente entre las actividades y las ciudades, localidades y el territorio de las regiones. Las ciudades consolidan su desarrollo a través de las redes de intercambio de mercancías, de conocimientos, de recursos, etc., que se conforman en la interacción (Hernández, 2015), generando fortalezas y debilidades sectoriales y territoriales en los centros urbanos de la red, que en el caso del turismo tiende a ligarse al mejoramiento de su competitividad.

Este progreso estará determinado por una amplia variedad de factores: el volumen y característica de los turistas (duración de la estancia, actividad, medio de transporte, forma de organización del viaje, etc.) (Bigñe, 2000), o la estructura de la economía receptora, los tipos de actividad turística, la diferencia en características socioculturales entre anfitriones y turistas; y la fragilidad del medio ambiente (Cooper, 2008). Los diversos impactos turísticos se pueden organizar en categorías atendiendo las características y la naturaleza de sus efectos: impactos económicos, sociales, culturales, políticos y ambientales.

En esta mejora se reconoce que el turismo ocasiona un impacto en las ciudades, y el mismo es el cambio notorio que se produce en las poblaciones naturales por efecto de esta actividad a zonas que estuvieron en completo aislamiento, afluencia que manifiesta preferencias por el turismo de sol y playa, ecoturismo, turismo de aventura, cultural, histórico, gastronómico o religioso. El caso más dramático generalmente radica en el cambio de comportamiento hacia actitudes hostiles y agresivas (Sarmiento, 2010).

\subsection{Las ciudades y la competitividad turística}


A partir de la década de los noventa se ha intentado ofrecer múltiples modelos de competitividad de los destinos turísticos asentados en las ciudades. Los autores que con mayor precisión y amplitud han definido la competitividad de estos espacios han sido Geoffrey Crouch y Brent Ritchie (1999), quienes la refieren como la capacidad "para crear valor añadido e incrementar, de esta forma, el bienestar nacional mediante la gestión de ventajas y procesos, atractivos, agresividad y proximidad, integrando las relaciones entre los mismos en un modelo económico y social". Los autores definen un destino turístico como el espacio o ámbito geográfico con rasgos propios de clima, cultura, atractivos, infraestructuras, servicios, equipamientos, precio, imagen y gestión, los cuáles, en términos de mercado, se posicionan en la mente de los consumidores. Un destino turístico está compuesto así por un número de atributos, que pueden estar basados en recursos naturales, creados, o abstractos, un conjunto de facilidades y servicios turísticos dirigidos a satisfacer las necesidades de los turistas o consumidores potenciales.

Dentro de los factores de atracción se destacan la fisiografía, cultura e historia, lazos con el mercado, actividades, acontecimientos especiales y superestructura, resumidos en factores como el fomento turístico, los recursos humanos y la profesionalización del sector hotelero, infraestructura y accesibilidad, así como los servicios complementarios al turismo. Estos son el núcleo básico que conforman los elementos primarios del atractivo del destino. La existencia de estos factores se convierte en una condición necesaria para la consecución de las ventajas competitivas de un destino. No está de más recalcar que estos factores deben manifestar un impacto económico, social y ambiental en el territorio (ver esquema 1).

Esquema 1. Modelo teórico de la investigación

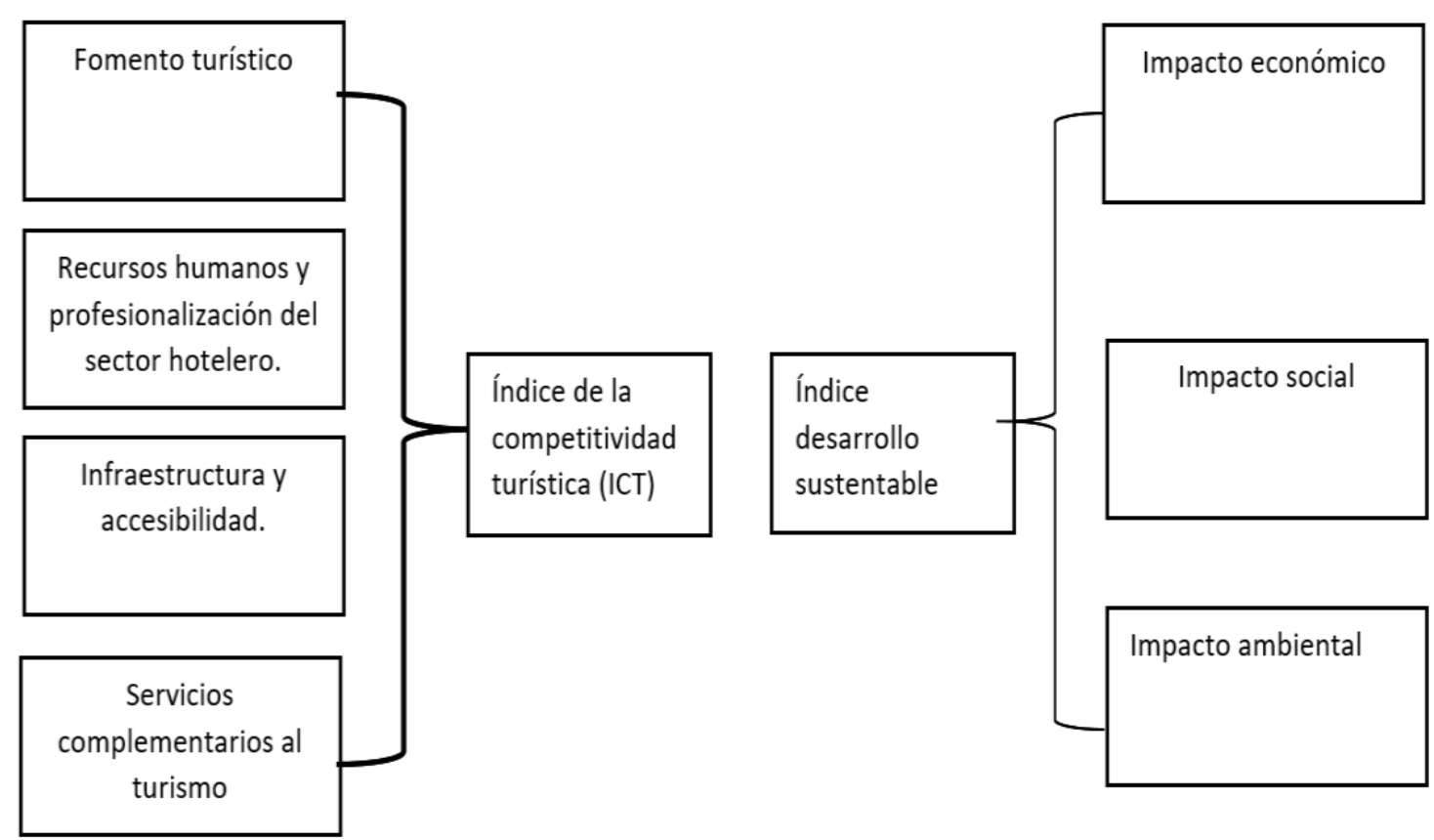

Fuente: Elaboración de los autores (Moncada, 2018) 
Lo anterior pone de manifiesto que en la realidad la relación del turismo con otras actividades de la ciudad es compleja, es decir, es multifuncional, multicausal e interdisciplinaria, ligada al "desarrollo sustentable" de la población, y uno de cuyos propósitos es contribuir a la identificación de las políticas públicas más convenientes para promover el bienestar económico, social y ambiental de la población que habita la red generada por las ciudades a partir de la actividad turística.

En esta relación, la asociación "competitividad turística-desarrollo sustentable" genera fortalezas y debilidades en los territorios y las redes de ciudades donde se manifiesta. Las fortalezas impulsan la sustentabilidad del desarrollo, las debilidades dificultan u obstaculizan la misma. Sectorialmente, se espera que el factor ambiental de las ciudades sea el que mejor fundamente las fortalezas de esta relación, debido a que desde su origen las acciones que del mismo derivan están orientadas a la mejora ambiental, en tanto que se espera que el "factor recursos humanos", debido a que requiere un periodo de tiempo relativamente amplio derivado de la capacitación, sea una de las principales causas de las debilidades de esta relación.

Por otro lado, también se esperaría que territorialmente las ciudades equipadas para el turismo fundamenten la fortaleza de la relación competitividad turística-desarrollo sustentable, debido a que de esta actividad derivaría la derrama económica y las acciones respectivas para la mejora de la sustentabilidad y la calidad de vida de la población; por el contrario, las ciudades no-turísticas podrían ser la causa de las debilidades de esta relación debido a que carecen de la dinámica del turismo. Estas reflexiones conceptuales constituyen el referente del análisis empírico del presente artículo.

\section{PROCEDIMIENTO METODOLÓGICO \\ 3.1 Modelo de análisis}

El modelo metodológico establece la relación entre el turismo y el desarrollo en las ciudades de Oaxaca durante el periodo 2000-2015. En el esquema 2 se especifican las dimensiones económica, social y ambiental que intervienen en el mismo.

Esquema 2: Modelo metodológico del análisis

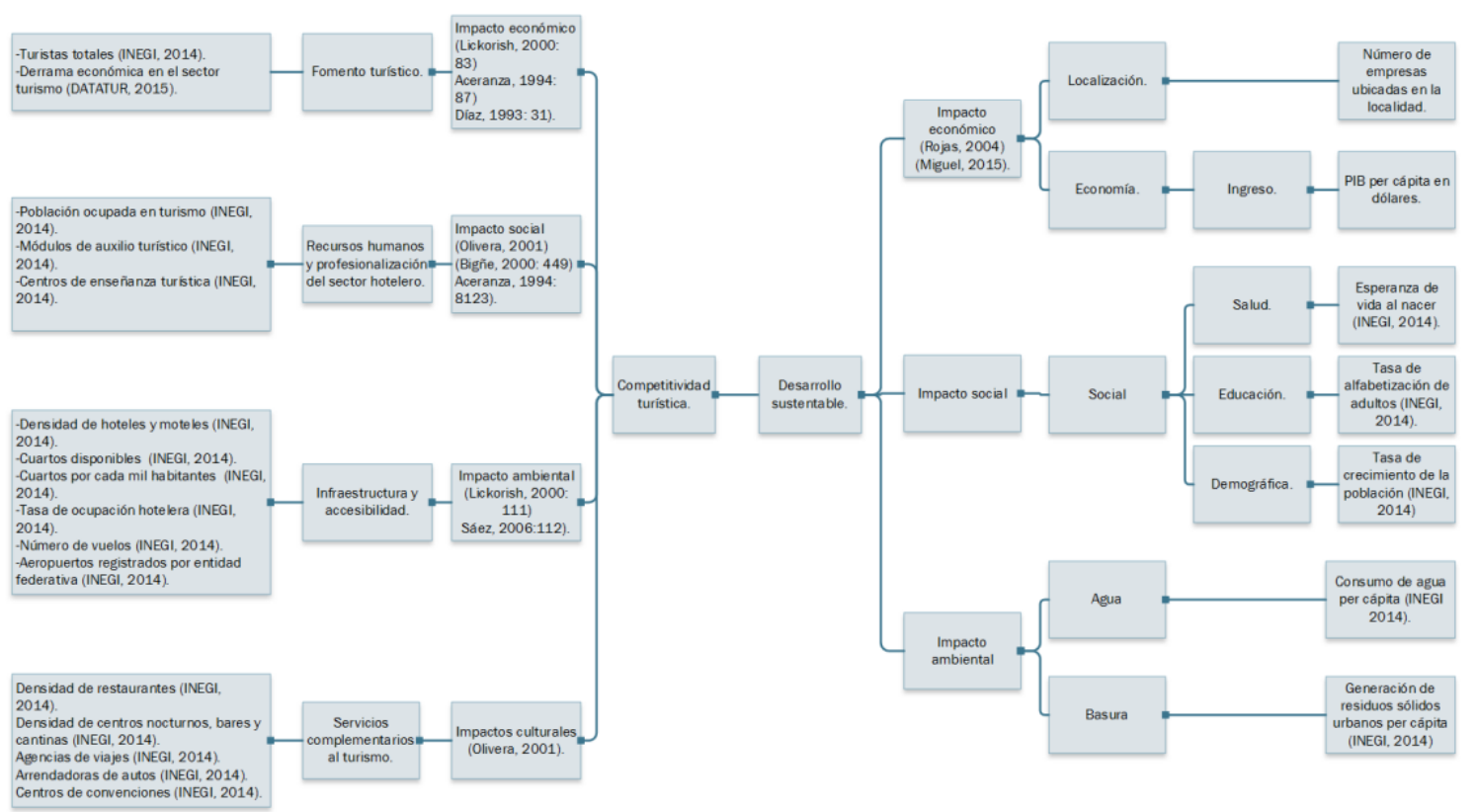

Fuente: Adaptación con datos obtenidos de la metodología (Solís 2013) encontrado en (Moncada, 2018) 
El modelo propone que un aumento de los indicadores del turismo, como el fomento turístico, de recursos humanos, la profesionalización del sector hotelero y servicios complementarios al turismo, se refleja en el aumento del desarrollo sustentable. Es importante mencionar que este modelo también considera el impacto económico, ambiental y social que se manifiesta en la población de la ciudad.

\subsection{Instrumentos de la información}

Se seleccionaron indicadores de población de los Censos y Conteos de la Población (INEGI 2000, 2005, 2010 \& 2015); del desarrollo, en este caso el índice de desarrollo humano (IDH) y el PIB (PNUD México, 2014); como indicadores ambientales el consumo de agua por habitante, que es la cantidad de agua que consume una persona para beber, limpieza, preparación de alimentos y otros usos domésticos; así como la generación de residuos sólidos para los municipios más urbanizados del estado de Oaxaca (INEGI, 2000).como el fomento turístico, los recursos humanos y profesionalización del sector hotelero; la infraestructura y accesibilidad, así como los servicios complementarios al turismo se tomaron de la Organización Mundial de Turismo (OMT) en 2010 y SECTUR 2012. En el cuadro 1 se especifican las variables detalladas en cuestión a su dimensión, indicadores y la ecuación correspondiente, tanto del desarrollo sustentable como de la competitividad turística.

Cuadro 1. Descripción del modelo teórico de la investigación

\begin{tabular}{|c|c|c|c|}
\hline VARIABLES & DIMENSIONES & INDICADORES & ECUACIÓN \\
\hline \multirow{3}{*}{$\begin{array}{l}\text { Índice de } \\
\text { desarrollo } \\
\text { sustentable } \\
\text { (IDS) }\end{array}$} & $\begin{array}{l}\text { Factor económico } \\
\text { (IIE) }\end{array}$ & $\begin{array}{l}\text { - Unidades económicas (UE) } \\
\text { - Ingreso per cápita (I) }\end{array}$ & \multirow{7}{*}{ 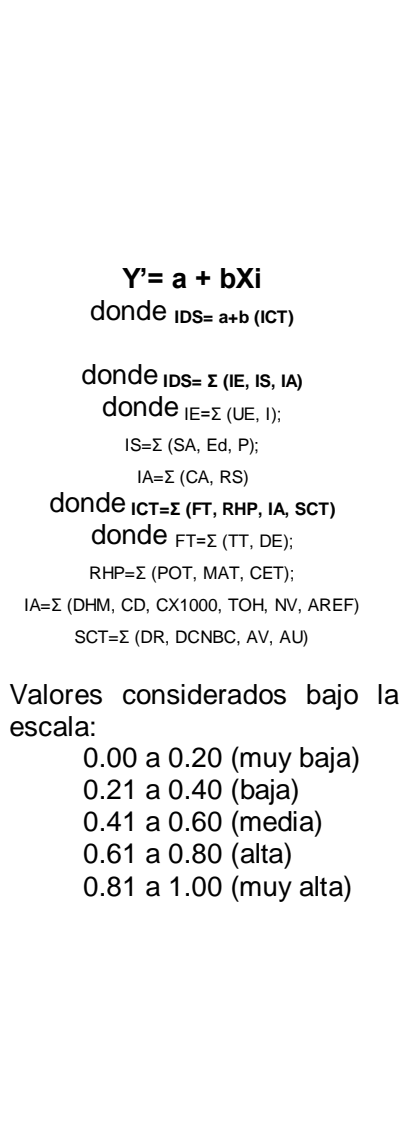 } \\
\hline & $\begin{array}{l}\text { Factor social } \\
\text { (IIS) }\end{array}$ & $\begin{array}{l}\text { - Salud (SA) } \\
\text { - Educación (Ed) } \\
\text { - Población (P) }\end{array}$ & \\
\hline & $\begin{array}{l}\text { Factor ambiental } \\
\text { (IIA) }\end{array}$ & $\begin{array}{l}\text { - Consumo de agua por habitante (CA) } \\
\text { - Generación de residuos sólidos (RS) }\end{array}$ & \\
\hline \multirow{4}{*}{$\begin{array}{l}\text { Índice de la } \\
\text { competitividad } \\
\text { turística (ICT) }\end{array}$} & $\begin{array}{l}\text { Fomento turístico } \\
\text { (IFT) }\end{array}$ & $\begin{array}{l}\text { - Turistas totales(TT) } \\
\text { - Derrama económica (DE) }\end{array}$ & \\
\hline & $\begin{array}{l}\text { Recursos humanos y } \\
\text { profesionalización del } \\
\text { sector hotelero. (IFR) }\end{array}$ & $\begin{array}{l}\text { - Población ocupada en el turismo(POT) } \\
\text { - Módulos de auxilio turístico (MAT) } \\
\text { - Centros de enseñanza turística(CET) }\end{array}$ & \\
\hline & $\begin{array}{l}\text { Infraestructura y } \\
\text { accesibilidad. } \\
\text { (IFT) }\end{array}$ & $\begin{array}{l}\text { - Densidad de hoteles y moteles(DHM) } \\
\text { - Cuartos Disponibles(CD) } \\
\text { - Cuartos por cada mil } \\
\text { habitantes(Cx1000H) } \\
\text { - Tasa de ocupación hotelera(TOH) } \\
\text { - Número de vuelos(NV) } \\
\text { - Aeropuertos registrados por entidad } \\
\text { federativa(AREF) }\end{array}$ & \\
\hline & $\begin{array}{l}\text { Servicios } \\
\text { complementarios al } \\
\text { turismo. } \\
\text { (ISC) }\end{array}$ & $\begin{array}{l}\text { - Densidad de restaurantes(DR) } \\
\text { - Densidad de centros nocturnos, bares y } \\
\text { cantinas(DCNBC) } \\
\text { - Agencias de viajes (AV) } \\
\text { - Arrendadora de autos(AU) }\end{array}$ & \\
\hline
\end{tabular}


La valoración de los índices obtenidos toma como referente la escala de: 0.00 a 0.20 (muy baja), 0.21 a 0.40 (baja), 0.41 a 0.60 (media), 0.61 a 0.80 (alta); y 0.81 a 1.00 (muy alta).

\subsection{Procedimiento metodológico}

El análisis de la información se fundamenta en un enfoque cuantitativo derivado de la aplicación de la "técnica estadística de regresión", para obtener la asociación existente entre las variables, donde Y: "desarrollo sustentable" (IDS) y Xi: "competitividad turística" (ICT). Este análisis desarrolla un modelo matemático que expresa la relación entre dos variables y estima el valor de la variable dependiente. La ecuación 1 de la forma general de la regresión lineal es:

$$
\left.\mathrm{Y}^{\prime}=\mathrm{a}+\mathrm{bXi} \text { (ecuación } 1\right)
$$

donde $\mathrm{Y}^{\prime}$ : valor predictivo de la variable Y para un valor Xi seleccionado; a: intersección de la línea recta con el eje Y; b: pendiente de la línea recta, o el cambio promedio en $\mathrm{Y}^{\prime}$ por cada cambio en una unidad (ya sea aumentando o disminuyendo) de la variable independiente $\mathrm{Xi}$; $\mathrm{Xi}$ : valor que se elige para la variable independiente. A los valores a y b de la ecuación de regresión se les conoce como coeficientes de regresión.

La estandarización de las unidades de los indicadores se construyó a través de la ecuación 2 para obtener el índice de cada componente (IC), basada en la metodología de (Sepúlveda, 2008)

Cuadro 2. Ecuaciones

\begin{tabular}{|c|c|}
\hline \multicolumn{2}{|c|}{$\begin{array}{c}\text { Ecuación } 1 \text { | Función del desarrollo sustentable en el } \\
\text { turismo }\end{array}$} \\
\hline$I_{D S}=f\left(I_{C T}\right)$ & Donde: \\
\hline & $\begin{array}{l}I_{D S}: \text { Índice del desarrollo } \\
\text { sustentable } \\
I_{C T}: \text { Índice de la competitividad } \\
\text { turística }\end{array}$ \\
\hline \multicolumn{2}{|c|}{ Ecuación 2 | Índice de cada componente } \\
\hline$I_{C}=\frac{V_{R}-V_{\min }}{V_{\operatorname{máx}}-V_{\min }}$ & $\begin{array}{l}\text { Donde: } \\
I_{C}: \text { Índice de componente } \\
V_{R}: \text { Valor real } \\
V_{\text {máx }}: \text { Valor máximo } \\
V_{\text {mín }}: \text { Valor mínimo }\end{array}$ \\
\hline
\end{tabular}

\section{Fuente: Elaboración de los autores}

Para validar los resultados de la regresión y comprobar las hipótesis se toma como referencia el valor del coeficiente de correlación derivado de la regresión entre el valor del "índice de desarrollo sustentable" (IDS) y el "índice de competitividad turística" (ICT) de las ciudades durante 2000-2015. La correlación será válida si

$$
\text { Corr }(\text { IDS-ICT) }>0.60
$$


y que además posea una significancia $\geq 90 \%$. El valor obtenido en sentido positivo o negativo, se evaluará con la escala: 0.00 a 0.20 (muy baja), 0.21 a 0.40 (baja), 0.41 a 0.60 (media), 0.61 a 0.80 (alta); y 0.81 a 1.00 (muy alta).

\section{RESULTADOS}

\subsection{El contexto del desarrollo de las ciudades de Oaxaca}

El estado de Oaxaca se compone de 570 municipios. Se localiza en el sur de México en las coordenadas $17^{\circ} 0^{\prime}$ latitud norte, $96^{\circ} 47^{\prime}$ longitud oeste, y a una altitud de 1,560 metros sobre el nivel del mar. En el presente artículo se analizan diecisiete ciudades (mapa 1), 15 de ellas con población mayor a 15,000 habitantes, de las cuales, cinco son promocionadas expresamente como "ciudades turísticas" (la Zona Metropolitana de Oaxaca, Puerto Escondido, La Crucecita Huatulco, Tuxtepec).

\section{Mapa 1. Ciudades de Oaxaca, México: Ubicación geográfica}

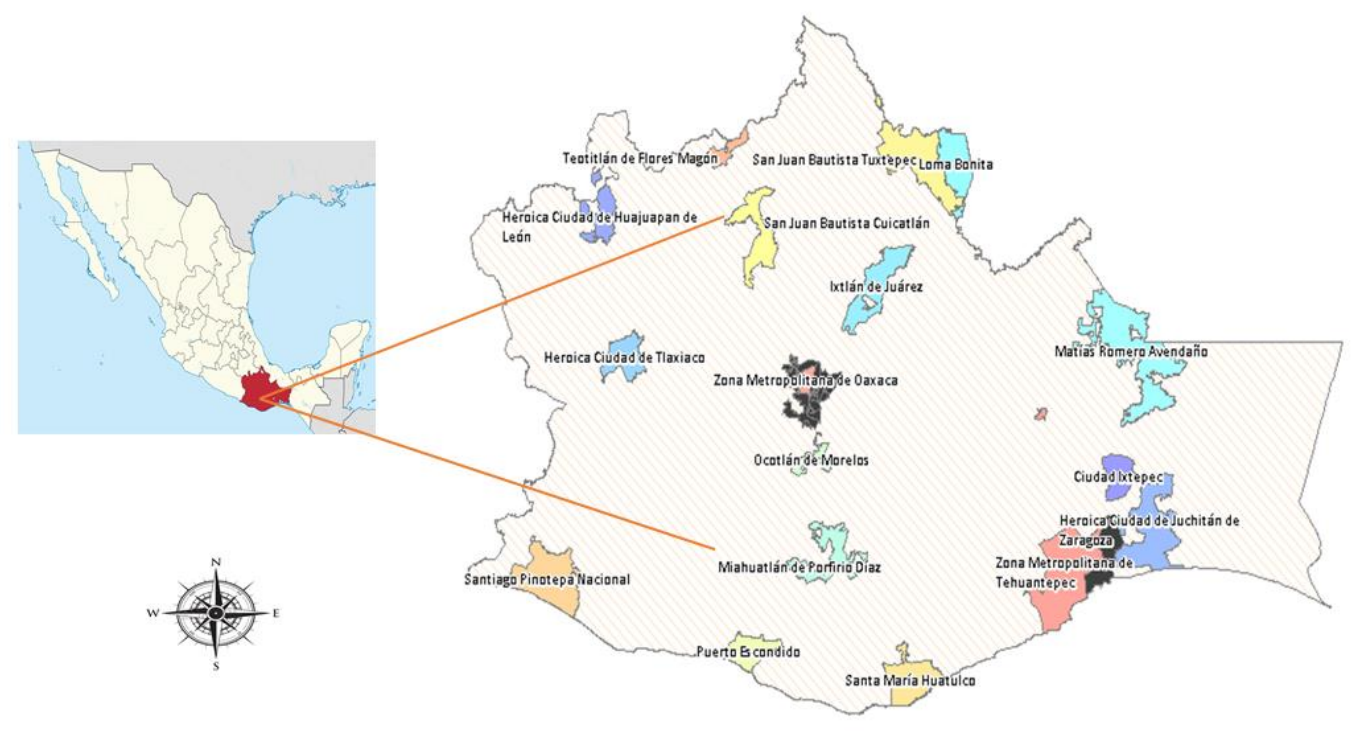

Fuente: Elaboración de los autores con apoyo del Software Mapa Digital versión 6.1 a partir del Marco Geoestadístico Nacional 2010 (INEGI). Encontrado en (Moncada, 2018)

Una característica particular de Oaxaca es que es el estado que posee la mayor diversidad biocultural de México, y este aspecto resalta su importancia en el campo del turismo. La existencia de 16 grupos étnicos y 177 variantes lingüísticas en esta entidad, se refleja en una de las celebraciones turísticas culturales más notorias de este estado, la "Fiesta de la Guelaguetza", que reúne la música, bailes, vestimenta, costumbres, idiomas y gastronomía de los grupos étnicos oaxaqueños.

Territorialmente, la entidad también está ligada a la presencia de prácticamente todos los ecosistemas y tipos de vegetación que caracterizan al planeta, desde matorrales espinosos en las zonas áridas, bosques tropicales siempre verdes en las zonas más húmedas, y desde arrecifes de coral y manglares en la costa del Pacífico hasta bosques de niebla, encinares, pinares y bosques de oyamel en las montañas más altas 
(De Ávila, 2008: 565-573), lo cual se refleja en los atractivos de sol y playa, ecoturismo, turismo de aventura, cultural, Histórico, Gastronómico, Religioso, turismo de negocios que posee el estado de México.

Como se muestra en el cuadro 3, las ciudades analizadas se denominan "red de las ciudades de Oaxaca" (RCoAx), en el que se indica el nombre oficial y el nombre cotidiano; éste último es el que se utilizará a lo largo del texto, con excepción de la Zona Metropolitana de Tehuantepec y la Zona Metropolitana de Oaxaca que se denominarán con las abreviaturas ZMT y ZMO. También se muestra el tipo de turismo predominante en las mismas. Las abreviaturas se utilizarán en los mapas, gráficas y figuras del texto.

\section{Cuadro 3. Ciudades de Oaxaca, México}

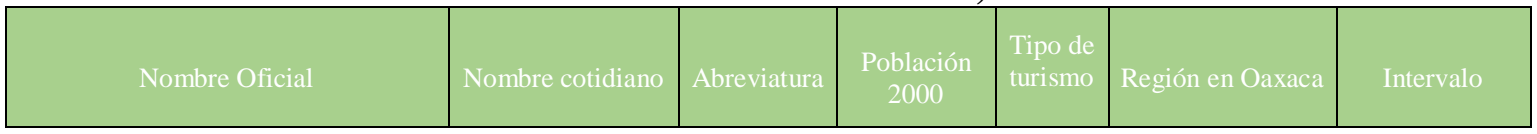

\begin{tabular}{|c|c|c|c|c|c|c|}
\hline Ixtlán de Juárez & Ixtlán & It & 8268 & $\mathrm{ECO}$ & Sierra Norte & \multirow{7}{*}{$\begin{array}{l}\text { Pequeñas } \\
\text { ciudades }\end{array}$} \\
\hline San Juan Bautista Cuicatlán & Cuicatlán & $\mathrm{Cu}$ & 9945 & $\mathrm{ECO}$ & Cañada & \\
\hline Ciudad Ixtepec & Ixtepec & Ix & 22,675 & EMP & Istmo & \\
\hline Loma Bonita & Loma Bonita & LB & 40,877 & CULT & Papaloapan & \\
\hline Miahuatlán de Porfirio Díaz & Miahuatlán & $\mathrm{Mh}$ & 32,555 & GAST & Sierra Sur & \\
\hline Ocotlán de Morelos & Ocotlán & Oc & 18,183 & CULT & Valles Centrales & \\
\hline Puerto Escondido & Puerto Escondido & $\mathrm{PE}$ & 32,471 & PLAY & Costa & \\
\hline $\begin{array}{l}\text { Heroica Ciudad de Huajuapan de } \\
\text { León }\end{array}$ & Huajuapan & $\mathrm{Hj}$ & & EMP & & Medianas \\
\hline $\begin{array}{l}\text { Heroica Ciudad de Juchitán de } \\
\text { Zaragoza }\end{array}$ & Juchitán & $\mathrm{Jc}$ & 78,512 & EMP & Istmo & ciudades \\
\hline San Juan Bautista Tuxtepec & Tuxtepec & $\mathrm{Tx}$ & 133,913 & EMP & Papaloapan & \\
\hline Zona Metropolitana de Oaxaca & $\mathrm{ZMO}$ & $\mathrm{ZMO}$ & 501,283 & CULT & Valles Centrales & $\begin{array}{l}\text { Grandes } \\
\text { ciudades }\end{array}$ \\
\hline Zona Metropolitana de Tehuantepec & ZMT & ZMT & 145,567 & EMP & Istmo & \\
\hline
\end{tabular}

Fuente: Elaboración de los autores con base al Sistema de Información Municipal (CIEDD, 2014) encontrado en (Martínez et al., 2018)

En la RConx el $55.7 \%$ de sus habitantes vive en alguna ciudad y la tendencia es que tiende a continuar la urbanización de sus localidades. Demográficamente la RCoAx es muy desigual, predominando las pequeñas localidades. De sus ciudades destaca la Zona Metropolitana de Oaxaca (ZMO) a nivel nacional con una jerarquía intermedia. 
Oaxaca ocupa el segundo lugar en México con mayor población rural. De acuerdo a los datos censales de (INEGI, 2010) el 44.3\% de la población vive en localidades rurales. En la entidad se tienen registradas más de 10 mil localidades rurales (menores a 2,500 habitantes) y 156 localidades mixtas (rurales-urbanas de 2,500 a 14,999 habitantes). La dispersión de las localidades es influida por la accidentada orografía, la difícil accesibilidad y los patrones históricos de ocupación territorial por parte de la población. Igualmente presenta un nivel de urbanización en el cual más del $80 \%$ de sus 570 municipios se ubican en un rango de urbanización muy bajo, y menos del $15 \%$ entre alto y muy alto. Esto origina marginación y aislamiento, y refleja un nivel de desarrollo por debajo de la media nacional, con niveles no adecuados de productividad exigidos por la actividad económica actual, y con una orografía que hace costosa la cobertura de infraestructura económica y social hacia las poblaciones más aisladas y con reducido número de habitantes (habs.)

Por tal motivo, las ciudades de Oaxaca se comportan como un sistema disperso de lugares centrales, que manifiestan una baja interacción entre ellas (Miguel, 2004) En la actualidad, la RCoAx cuenta con tres ciudades que poseen más de 100,000 habs.: Tuxtepec, ZM T y la ZMO, esta última posee la mayor población del sistema. Dos ciudades, Juchitán y Huajuapan, cuentan con más de 50,000 habs., nueve ciudades poseen al menos 15,000 habs., y tres ciudades, Ixtlán, Cuicatlán y Teotitlán, cuentan con menos de 15,000 habs. (CONAPO, 2014)

Con base a los censos de población (INEGI), 5 ciudades (Miahuatlán, Huajuapan, Puerto escondido, Thaxico y Huatulco) poseen tasas de crecimiento de su población superior al 2\%. Matías romero es la única que manifestó una tasa de crecimiento poblacional negativa (-0. 7\%). Por extracto urbano, las ciudades entre 500 a 1000 mil habs., tuvieron un crecimiento poblacional anual de $1.95 \%$.

Cinco ciudades poseen un P IB per cápita por arriba de los \$15,000 dólares anuales (en orden descendente (Ixtlan, Tlaxiaco, Huajuapan, ZMT y ZMO). Habitantes de cinco ciudades ganan menos de esta cantidad, pero más de \$10,000 (Tuxtepec, Huatulco, Loma Bonita, Ocotlán, Matías Romero). El resto de las siete ciudades, posee un ingreso menor a $\$ 10,000$. Por extracto urbano, las ciudades de 50 a 100 mil hab., tuvieron un crecimiento anual de PIB per cápita de $4.33 \%$ (ver gráfica 1 ).

\section{Gráfica 1: Datos sociales, económicos y ambientales}




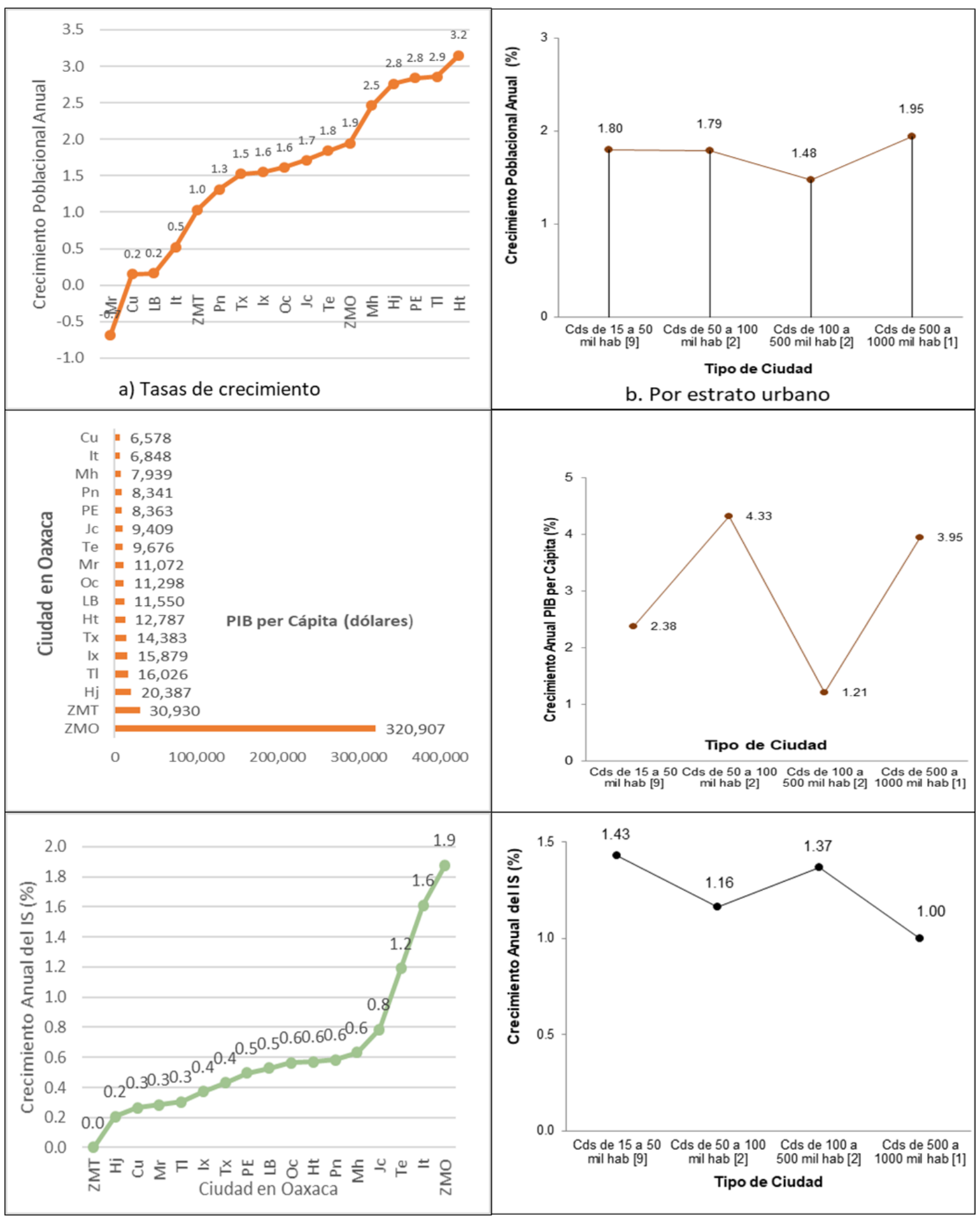

Fuente: El autor con datos del Censo de Población 2010 (INEGI)

En el aspecto económico (mapa 2), los ingresos de las ciudades analizadas han mostrado un estancamiento, mejorando su crecimiento a partir del 2015 en las ciudades de Tlaxiaco y Huajuapan, en la región de los pueblos mixtecos, en los cuales predomina el turismo gastronómico. En este periodo en el número de empresas localizadas hay un crecimiento en la ZMO correspondiente a la región de los Valles Centrales, predominantemente zapoteca, en los cuales destacan el turismo cultural y gastronómico. 
Mapa 2| Mapas del subíndice económico del desarrollo sustentable

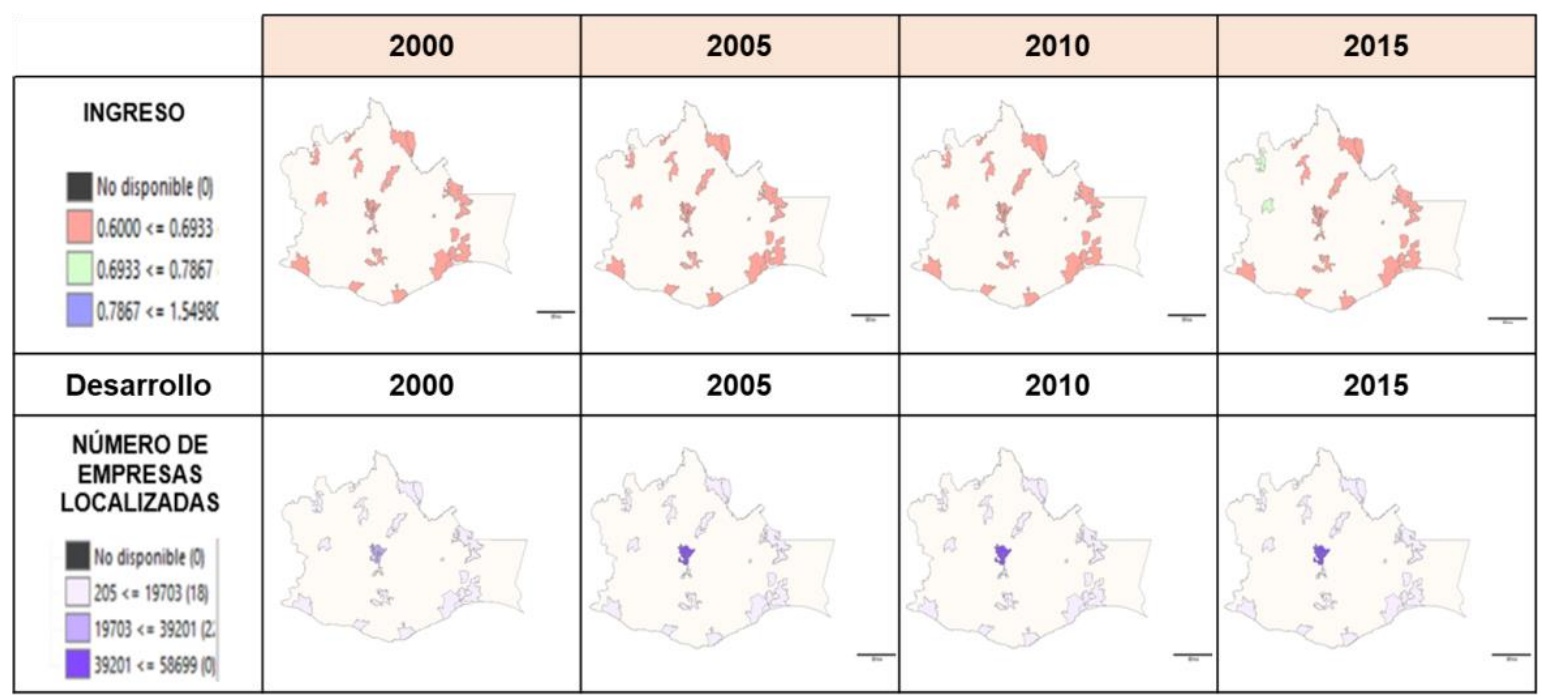

Fuente: Elaboración propia con apoyo del Software Mapa Digital versión 6.1 a partir del Marco Geoestadístico Nacional 2013 (INEGI, 2013).

En el aspecto social, entre 2000-2015 las ciudades que tuvieron un incremento en salud son: TeOtilán, IXTLan, y la ZMO con tasas superiores a 1\%. Por estrato urbano, las ciudades de hasta 50 mil habs. tuvieron el mayor crecimiento en este periodo (1.43\%). Pero en general no hubo un crecimiento notorio del índice de salud en las ciudades de Oaxaca (mapa 3). La esperanza de vida al nacer, que es uno de los indicadores que muestra las condiciones de salud de la población, era de 76 años para las mujeres, y de 70 años para los hombres en el 2015 (INEGI, 2015), (CONAPO, 2001). La ZMO es la que manifestó el mayor crecimiento en la esperanza de vida al nacer. En el 2015 este indicador también mejoró en las ciudades de Teotitlán y Cuicatrán. Es importante mencionar que la educación es parte fundamental del desarrollo de cualquier país (PNUD, 2011). Manifestó un crecimiento en el índice de educación en el año 2000 en la ZMO, pero durante 20052015 también hubo un aumento en otras dos ciudades: Puerto y Huatulco, ciudades en las cuales predomina el turismo de playa.

Mapa 3 | Mapas del subíndice social del desarrollo sustentable

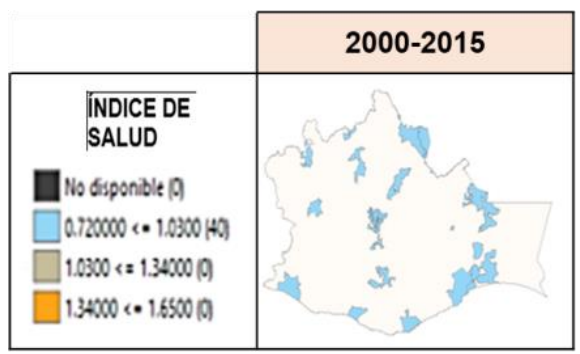




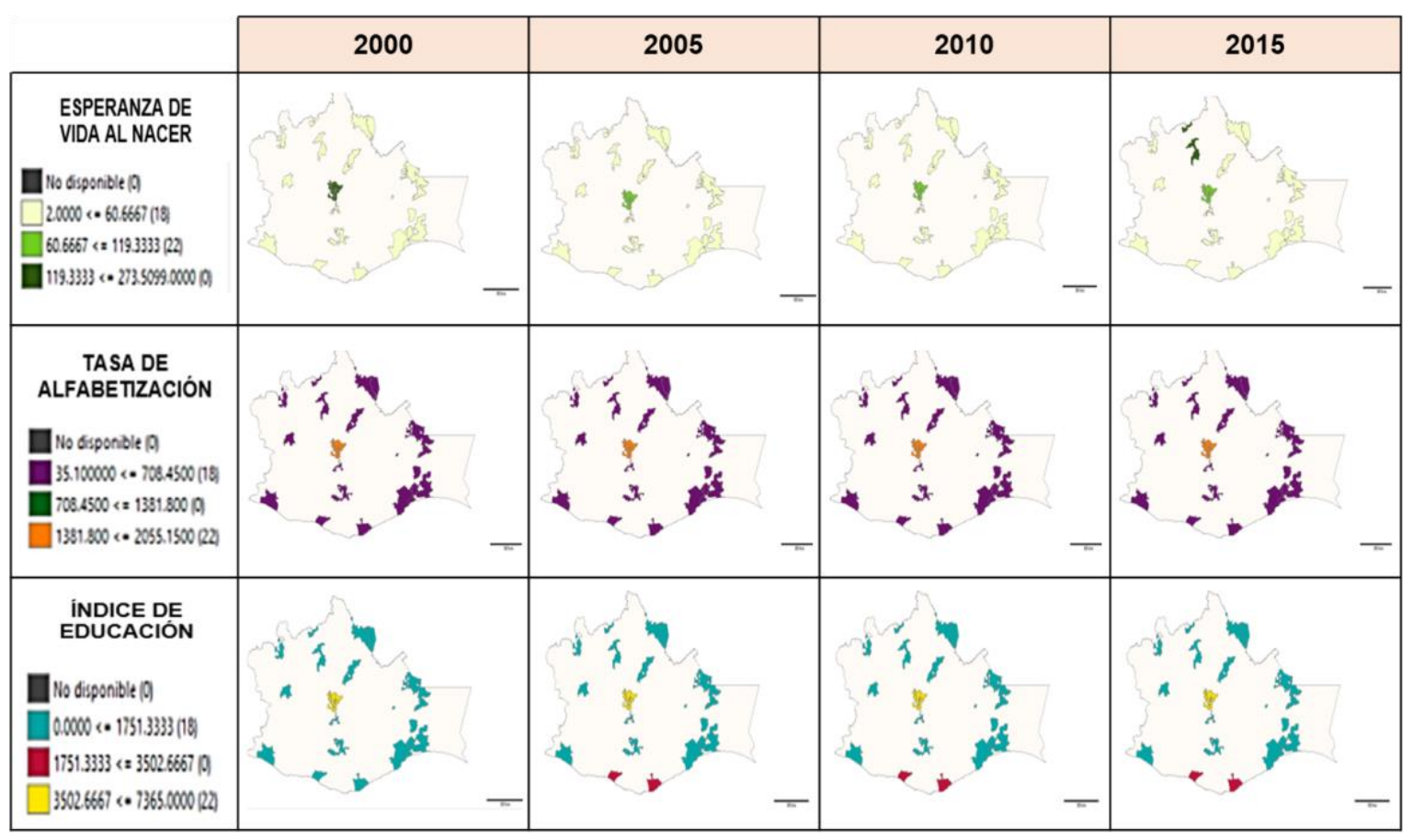

Fuente: Elaboración propia con apoyo del Software Mapa Digital versión 6.1 a partir del Marco Geoestadístico Nacional 2013 (INEGI, 2013).

En el aspecto ambiental, en el registro del volumen de residuos sólidos urbanos recolectados y de agua consumidos entre 2000-2015, en la RCoAx, sobresalió la ZMO correspondiente a la región de Valles Centrales. En lo que respecta al consumo de agua, la ciudad con mayor consumo de este vital líquido también es la ZMO, y manifestó un crecimiento importante en TUXTEPEC en el 2015 (mapa 4), ciudad en la cual predomina el turismo de negocios.

Mapa 4 | Mapas del subíndice ambiental del desarrollo sustentable 2000-2015

\begin{tabular}{|c|c|c|c|c|c|c|c|c|}
\hline & 2000 & & 2005 & & 2010 & & 2015 & \\
\hline $\begin{array}{c}\text { GENERACIÓN DE } \\
\text { RESIDUOS } \\
\text { SOLLIDOS } \\
\square \text { No disponible 10) } \\
\qquad 0<=78(18) \\
78<156(10) \\
\square 156<=234(22)\end{array}$ & $\begin{array}{l}4 \\
* 1 \\
* \\
*\end{array}$ & - & $\begin{array}{l}48 \\
47 \\
+3 \\
*\end{array}$ & 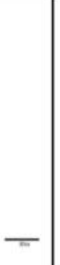 & $\begin{array}{r}17 \\
+4 \\
+\quad *\end{array}$ & 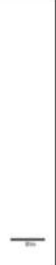 & $\begin{array}{l}18 \\
x y \\
+x \\
-1\end{array}$ & - \\
\hline 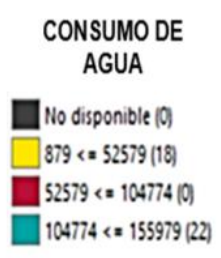 & $\left\{\begin{array}{l}3 \\
3 \\
3\end{array}\right.$ & - & $\left\{\begin{array}{l}3 \\
3 \\
3 \\
2\end{array}\right.$ & -1 & $\left\{\begin{array}{l}3 \\
3\end{array}\right.$ & - & $\begin{cases}4 & 7 \\
3 & 3 \\
3 & 1\end{cases}$ & $=$ \\
\hline
\end{tabular}

Fuente: Elaboración propia con apoyo del Software Mapa Digital versión 6.1 a partir del Marco Geoestadística Nacional 2013 (INEGI, 2013) 
La gráfica 2 resume los factores que influyen en el "desarrollo sustentable" de las ciudades de Oaxaca. Se observa que en general los mismos muestran variaciones a lo largo del periodo analizado. Los que manifestaron un mayor crecimiento son: el factor económico (IIE), que incluso supera al índice de desarrollo sustentable (IDS), el factor social (IIS) y en menor medida el factor ambiental (IIA), cuya tendencia es a la baja.

Gráfica 2. Factores del desarrollo sustentable 2000-2015

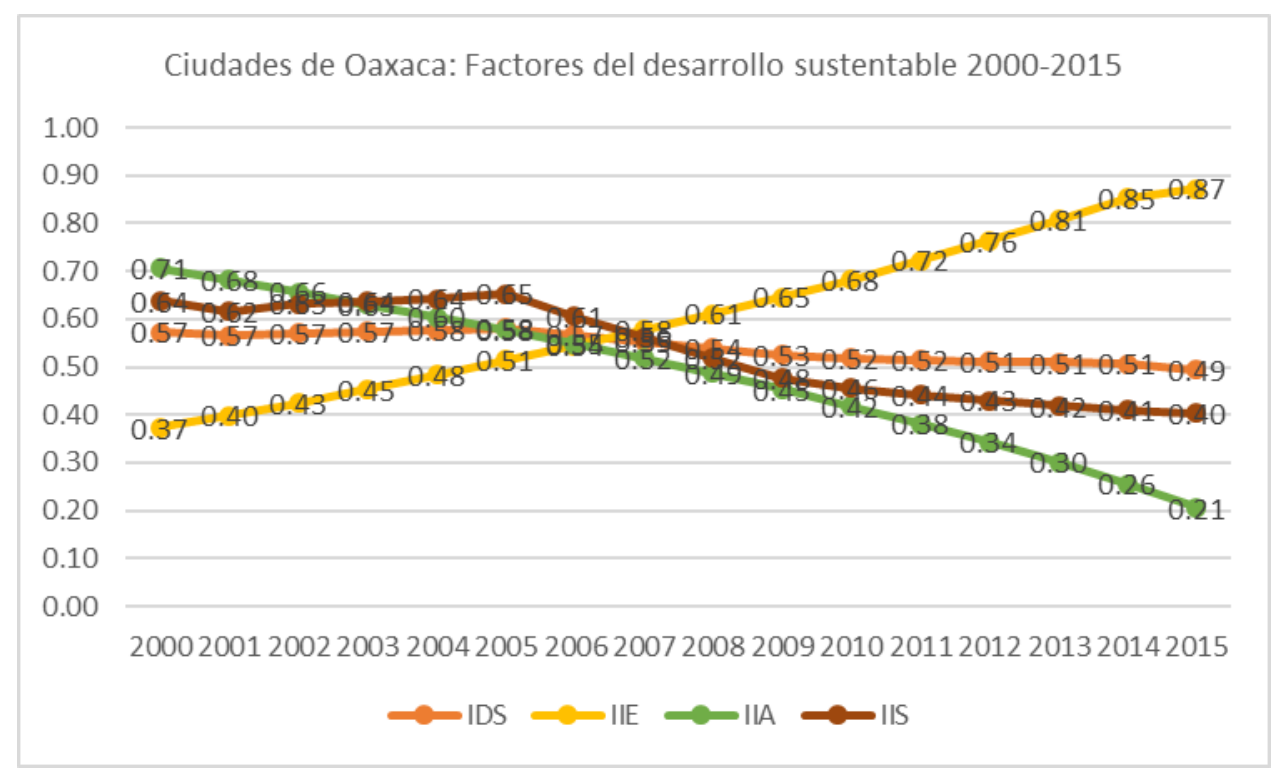

Fuente: Elaboración de los autores

La gráfica 2A resume los niveles del "desarrollo sustentable" de las ciudades de Oaxaca. Se observa que en general estos niveles muestran variaciones a lo largo del periodo analizado, pero con tendencias contradictorias de las ciudades al final del mismo. Las ciudades que manifestaron un mayor nivel fueron la ZMO y la ZMT; en tanto que las ciudades con menor desarrollo resultaron Loma, Teotitlán, y Thaxiaco. El resto de las ciudade se ubicaban en un nivel de desarrollo medio.

\section{Gráfica 2A. Ciudades de Oaxaca: Comportamiento del desarrollo sustentable}

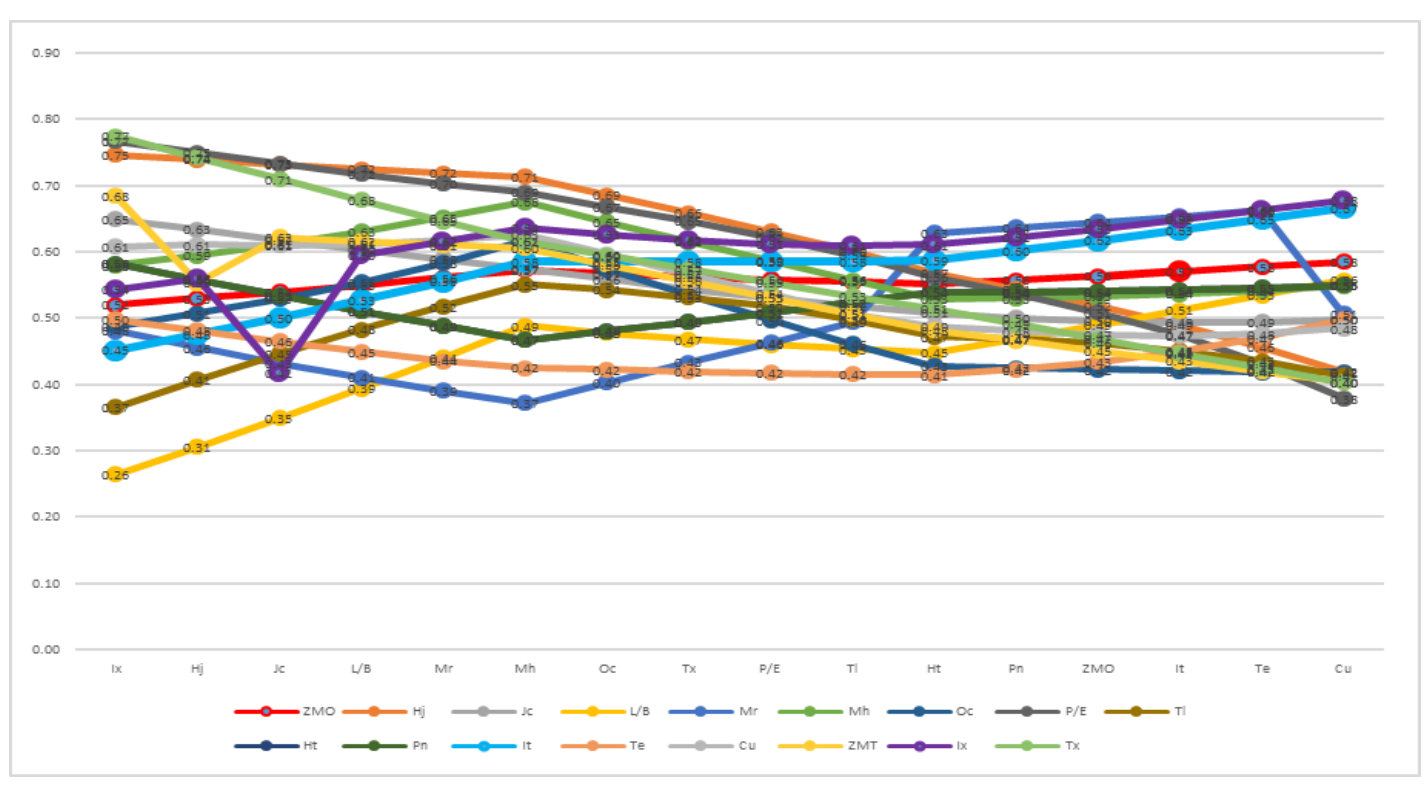

Fuente: Elaboración de los autores 


\subsection{El contexto del desarrollo turístico de las ciudades de Oaxaca}

El número de turistas totales que visitan las ciudades de Oaxaca se incrementó durante 2000-2015. Las ciudades con mayor captación fueron la ZMO $(368,124)$, Puerto Escondido $(317,068)$ y Huatulco $(160,381)$. Las ciudades de Ixtlán $(2,485)$, Ixtepec $(10,466)$, Teotitlán $(18,351)$, Ocotlán $(18,818)$ y Mromero $(21,986)$ son las que menos turismo captaron (gráfica 3).

La cantidad de cuartos disponibles que las ciudades de Oaxaca poseían eran: la ZMO (7,008), Huatulco (3,596), Puerto Escondido (3,073), Tuxtepec $(1,017)$ y la ZMT (876). Las ciudades con menor disponibilidad de cuartos eran Ixtlán (13), Cuicatlán (96), Ocotlán (99), TEotitrán (117) e Ixtepec (122). En cuanto a la ocupación hotelera, las ciudades que destacaron son: Huatulco (38.8\%), ZMT (38.0\%), Tuxtepec $(31.5 \%)$, ZMO (28.4\%), y Puerto Escondido (25.9\%). Durante 2010-2015 la ZMO la región de los Valles Centrales sobresalió, pero la ocupación hotelera también aumentó en la región Papaloapan. Específicamente la densidad de cuartos se ha incrementado durante 20052015 en las regiones de la Costa y los Valles Centrales.

En el número de centros de enseñanza turística, las ciudades que sobresalieron son: ZMO (13), Huatulco (8), Tuxtepec (4), y Huajuapan (4). El resto de las ciudades carecen de este servicio. El Istmo y los Valles Centrales destacaron en el 2000 por el número de centros de enseñanza turística; sin embargo, en el periodo 2005-2010 disminuyeron en el Istmo, y en el año 2015 aumentaron en la región de la Costa. Las ciudades que destacaron en módulos de auxilio turístico son: ZMO (5), ZMT (2), PUerto Escondido (1), Huatulco (1), y Juchitán (1). Durante2005 hubo un crecimiento de los módulos de auxilio turístico en la región de la Costa y el Istmo. Con respecto a las agencias de viajes, durante el año 2000 hubo un crecimiento en Valles Centrales y la Costa, pero éste disminuyó durante 2005-2010, volviendo a aumentar en el año 2015 en los Valles Centrales.

\section{Gráfica 3. Desarrollo turístico}

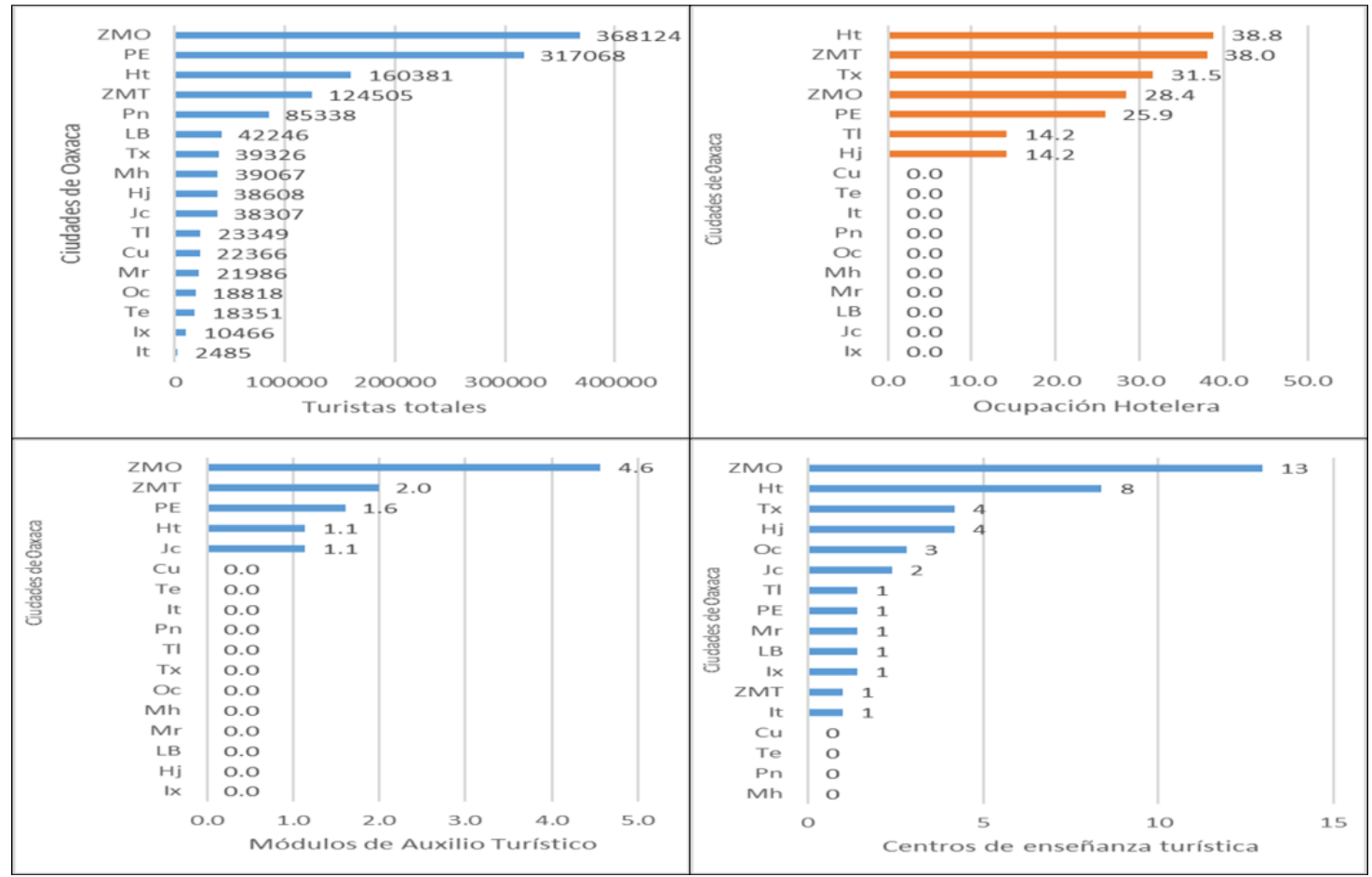

Fuente: El autor con datos del Censo de Población 2010 (INEGI) 
En Oaxaca la densidad de restaurantes también se ha incrementado entre 2000-2015. Sobresale la ZMO con 512 restaurantes, la sigue Huatulco (225) y Puerto Escondido (122). Las ciudades con menos restaurantes son: IxtLán (4), OcotLán (6), Loma bonita (8), y Cuicatlán (8). La densidad de restaurantes aumentó en todas las regiones, pero especialmente en la ZMT (13), Puerto Escondido y la región de la Costa.

Por lo que respecta a los centros nocturnos, bares y cantinas, las ciudades con mayor densidad son: Huatulco (62), la ZMO (41), Juchitán (25) y Tuxtepec (24). Las agencias de viajes se han incrementado en ciudades como la ZMO (46), Huatulco (27), y Cuicatlán (8). Las ciudades sin agencias de viajes son: Ixtlán, Juchitán, Loma bonita, Mromero, y Pinotepa (gráfica 4)

Gráfica 4. Recursos humanos y profesionalización del sector hotelero, infraestructura y accesibilidad, y servicios complementarios.

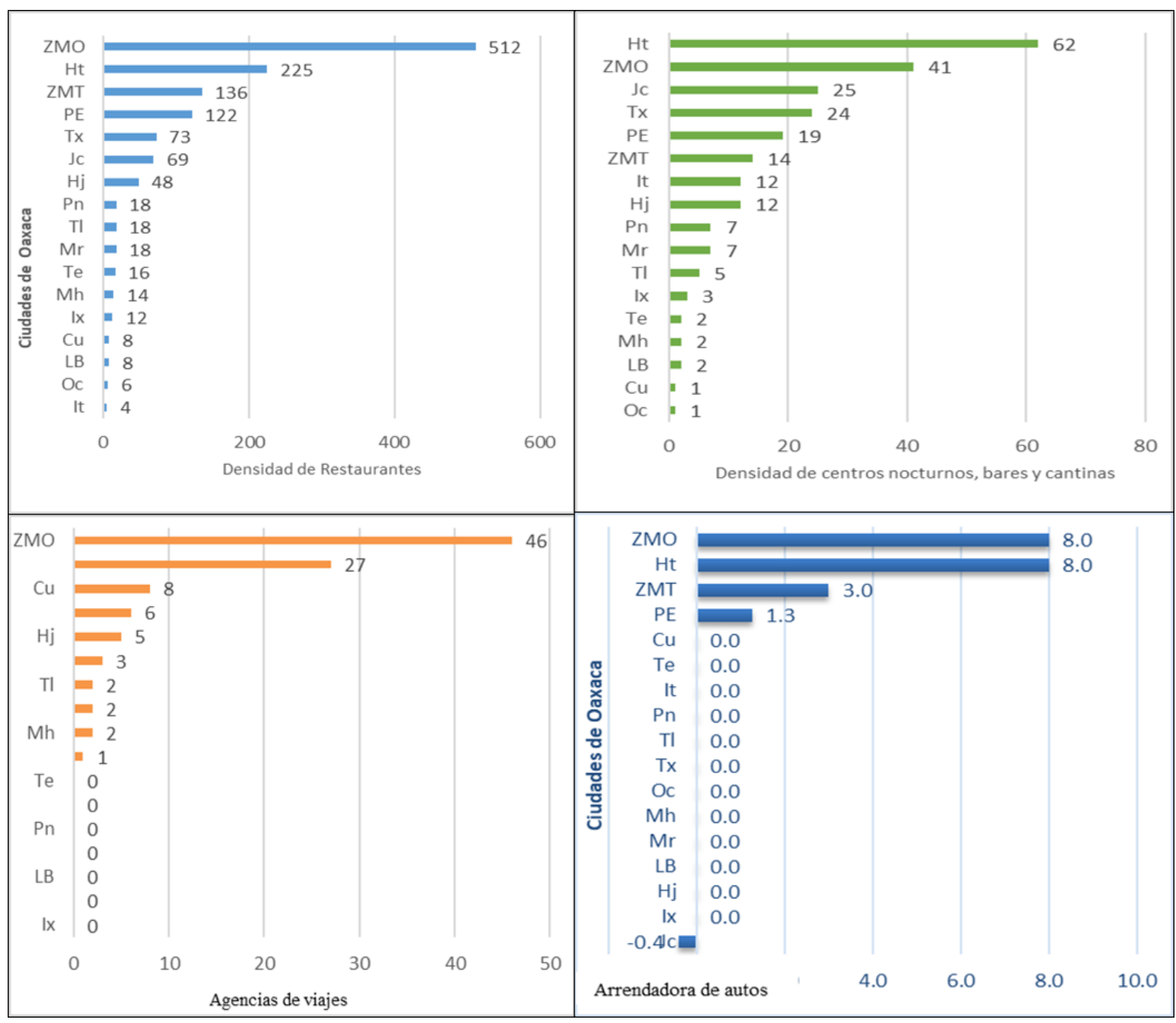

Fuente: El autor con datos del Censo de Población 2010 (INEGI)

En cuanto al número de vuelos de las 17 ciudades, solo tres ciudades tienen vuelos y son: ZMO (3364), Huatulco (1947) y Puerto Escondido (434), pues poseen aeropuerto. Las ciudades con menor número de establecimientos de hospedaje registrados son 8 ciudades: Ixtlán (1), Ixtepec (5), Ocotlán (5), Thaxiaco (7), Teotitlán (7), Cuicatlán (7) Mromero (9) y Miahuatlán (9). Las ciudades con mayor cantidad de arrendadores 
son: la ZMO (8) y Huatulco (8). En general, el crecimiento de las arrendadoras de autos ha disminuido en el resto de las ciudades, pero la ciudad con un crecimiento negativo ($0.4 \%$ ) es Juchitán. Existió un crecimiento en las arrendadoras de autos en el año 2000 en la región de los Valles Centrales y la región de la Costa, pero en el año 2015 el crecimiento destacó en los Valles Centrales (gráfica 5).

\section{Gráfica 5: Datos del fomento turístico.}

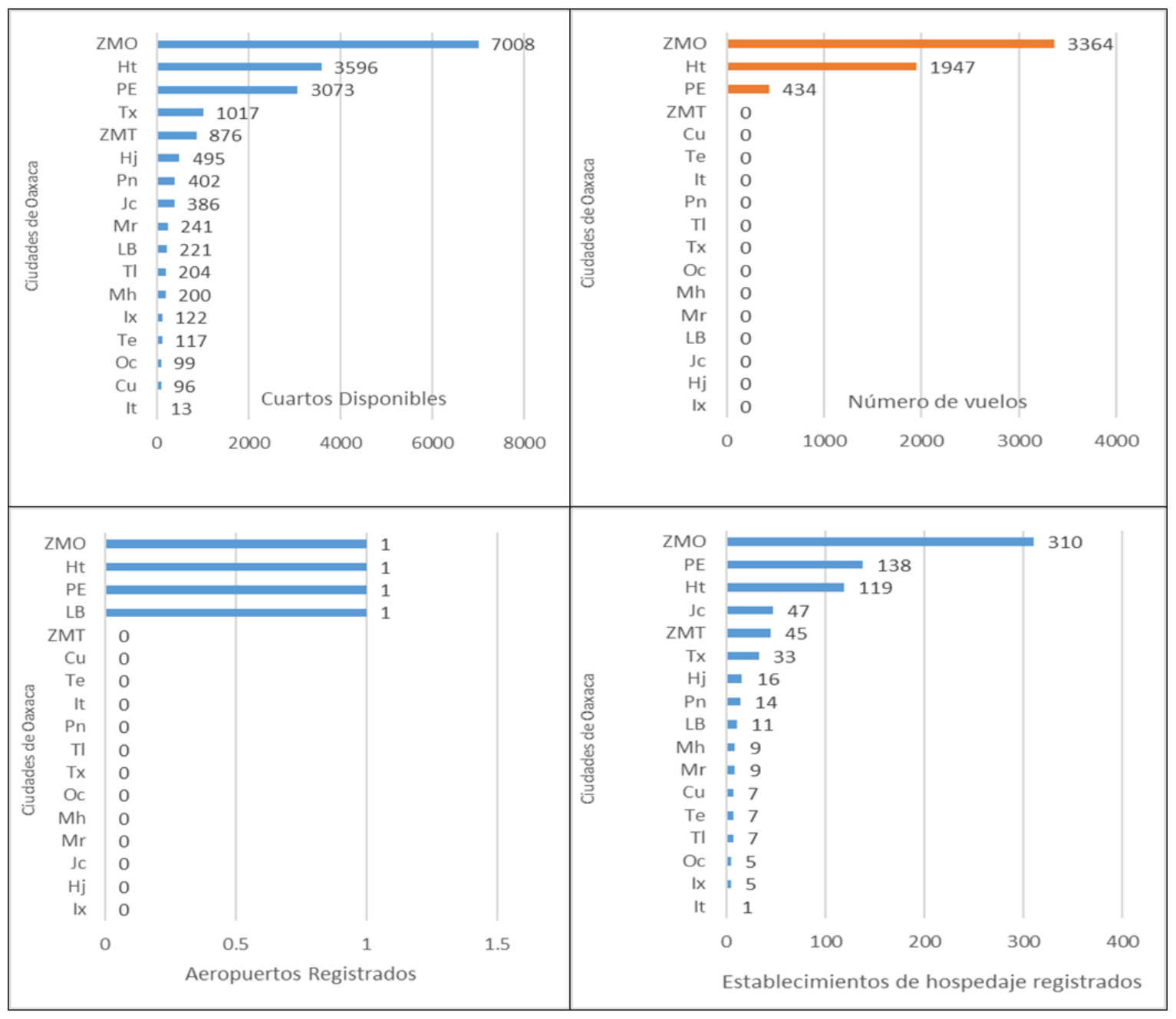

Fuente: El autor con datos del Censo de Población 2010 (INEGI) 
Mapa 5 | Mapas del subíndice del turismo

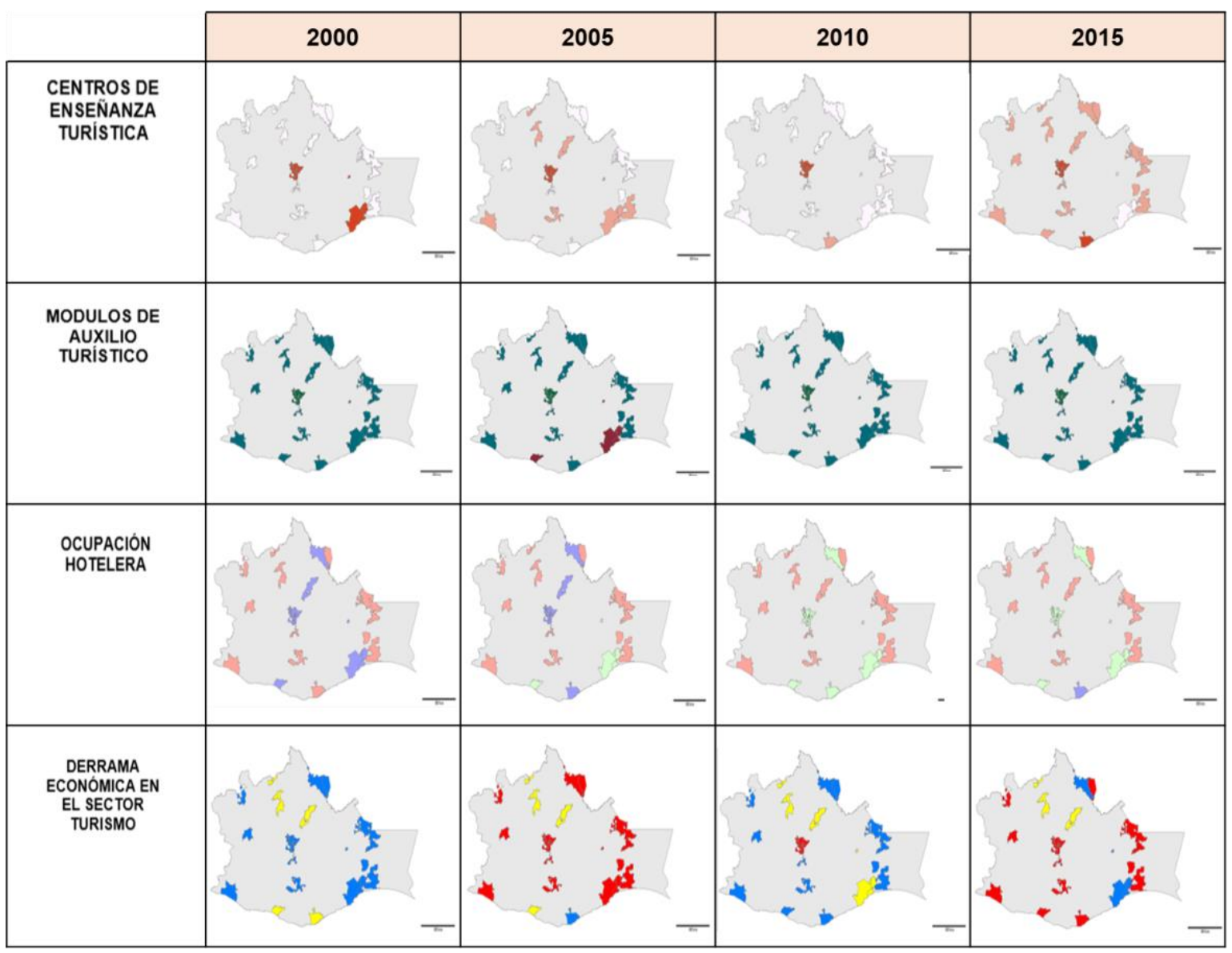

Fuente: Elaboración propia con apoyo del Software Mapa Digital versión 6.1 a partir del Marco Geoestadístico Nacional 2013 (INEGI, 2013). 


\section{Mapa 6 | Mapas del subíndice del turismo}

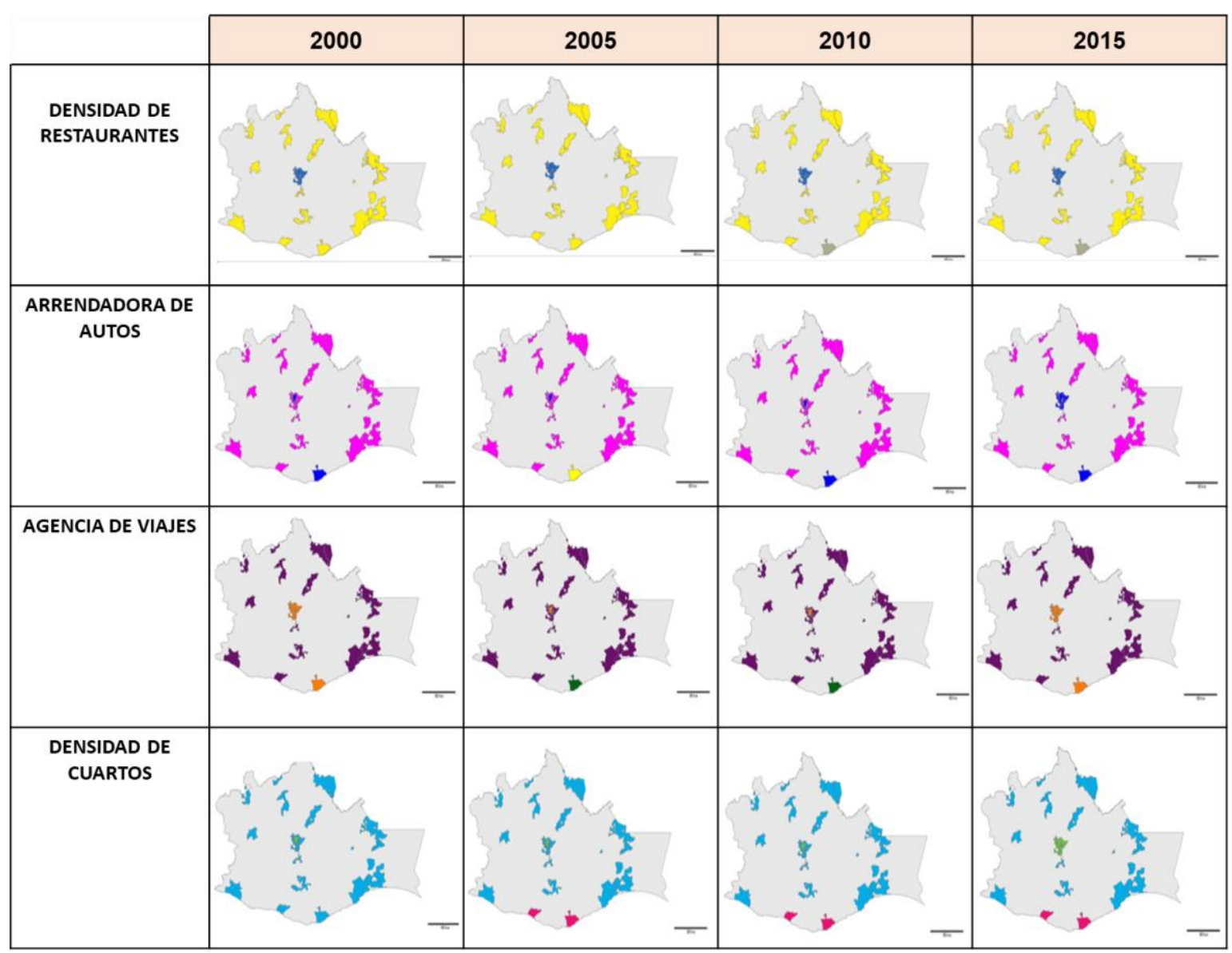

Fuente: Elaboración propia con apoyo del Software Mapa Digital versión 6.1 a partir del Marco Geoestadístico Nacional 2013 (INEGI, 2013).

La gráfica 6 resume los factores que influyen en la "competitividad turística" de las ciudades de Oaxaca. Se observa que en general estos factores muestran variaciones a lo largo del periodo analizado, pero con una tendencia al alza. Los factores que manifestaron un mayor crecimiento son: el de fomento turístico (IFT), que incluso supera al índice de competitividad turística (IT), el factor recursos humanos (IRH), el factor de infraestructura y accesibilidad (IFR) y en menor medida el factor de servicios complementarios (ISC), todos con una tendencia al alza. 
Gráfica 6. Factores turísticos 2000-2015

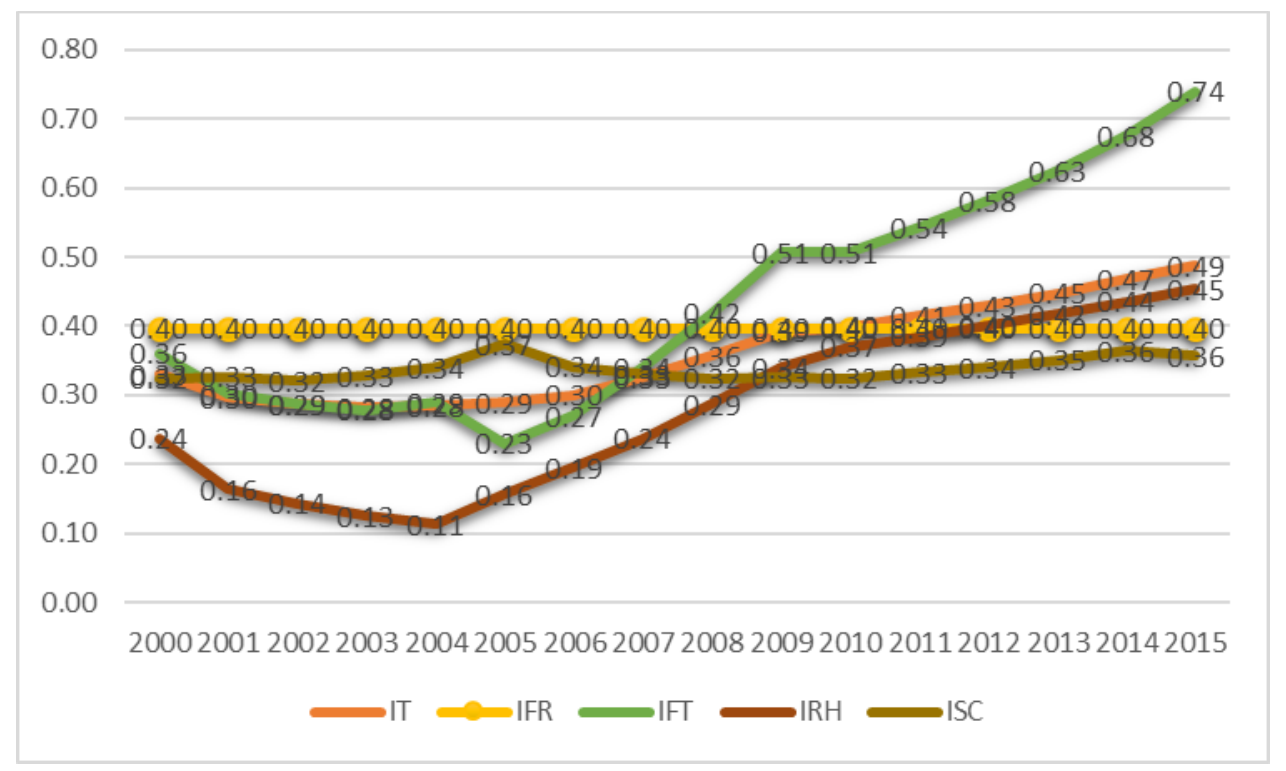

Fuente: Elaboración propia

La gráfica 7 muestra el comportamiento de la "competitividad turística" de las ciudades de Oaxaca. En la misma se observa un comportamiento variable durante 20002015 de todas las ciudades, pero con una tendencia a la baja de todas ellas. Las ciudades que destacan con una mayor competitividad turística fueron PUerto ESCONDido (con un valor del índice de 0.8), Huatulco (0.5), así como la ZMO, y las ciudades con menor competitividad fueron Cuicatlán (0.2), Teotitlán (0.2) y Pinotepa (0.1). El resto de las ciudades manifestó un comportamiento intermedio.

Gráfica 7. Ciudades de Oaxaca: Comportamiento de la competitividad turística de las ciudades de Oaxaca 2000-2015.

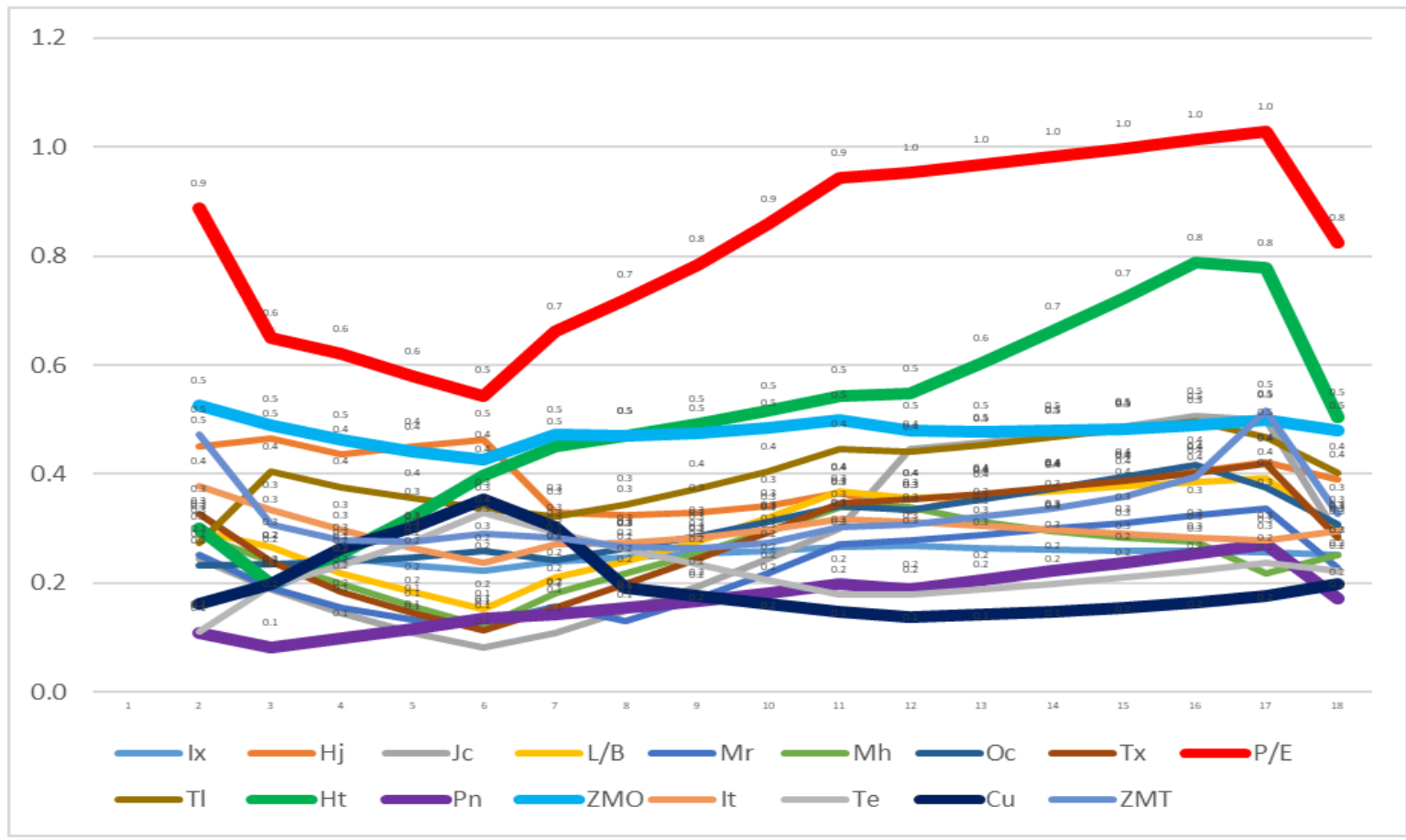

Fuente: Elaboración de los autores con datos de los censales (2000-2015, INEGI). 
En retrospectiva, puede decirse que durante 2000-2015 las ciudades con mayor crecimiento económico, debido al turismo gastronómico, cultural y de "nostalgia" derivado de la visita de los migrantes, fueron las pertenecientes a la región Mixteca. Durante este periodo las ciudades de la Costa, que destacan por el turismo de playa, lograron la mayor oferta turística, son generadoras de empleo y motor de crecimiento económico. En la región de la Sierra Norte y la Cañada, con un ecoturismo, diversidad y belleza natural, sus ciudades lograron destacar por su biodiversidad, gastronomía, medicina tradicional y sus paisajes. Las ciudades de la región del Papaloapan son las que poseen las mejores posibilidades de recursos naturales como el abasto de agua para la mejora de su oferta hotelera, destacando por su turismo cultural.

Las ciudades de los Valles Centrales se encuentran relativamente estancadas en su economía, pero poseen la mayor centralidad político-administrativa de la RCoAx, así como la mayor infraestructura y servicios para las actividades turísticas de tipo cultural y gastronómico. Las ciudades de la Sierra Sur poseen alternativas gastronómicas y de paisajes naturales derivados del turismo gastronómico, pero son las más débiles de la red. En general, todas las regiones del estado de Oaxaca combinan costumbres, tradiciones y biodiversidad como atractivos turísticos, y poseen un potencial turístico a desarrollar sobre todo en el campo de la gastronomía, pero todas manifiestan dificultades para lograr la sustentabilidad de su desarrollo (mapa 7).

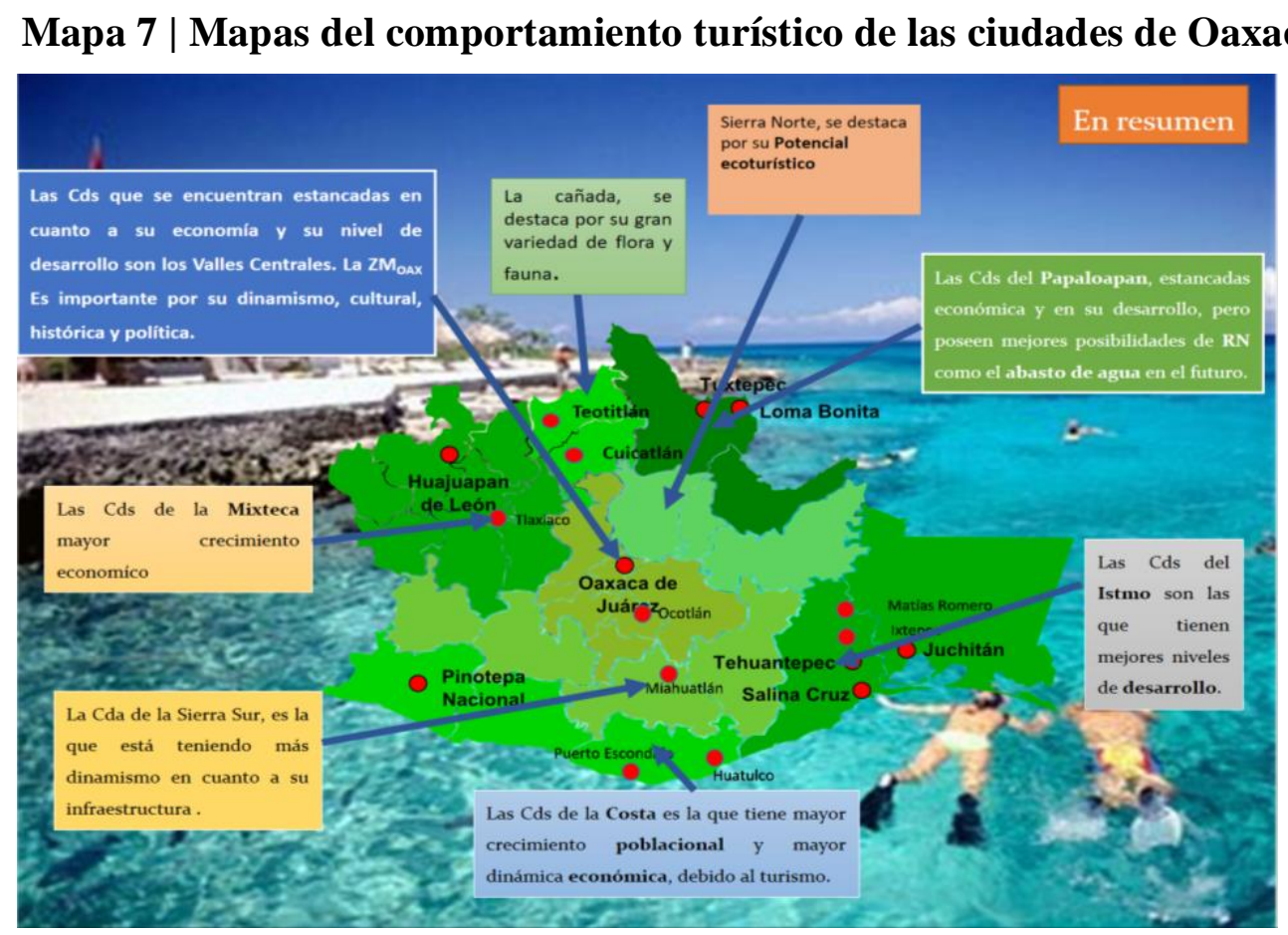

Fuente: Elaboración propia con apoyo del Software Mapa Digital versión 6.1 a partir del Marco Geoestadístico Nacional 2013 (INEGI, 2013).

\section{CONCLUSIONES, DISCUSIÓN Y RECOMENDACIONES: LA RELACIÓN DEL DESARROLLO SUSTENTABLE Y TURÍSTICO DE LAS CIUDADES DE OAXACA}

Según lo analizado, durante 2000-2015 en el proceso de "desarrollo sustentable" (IDS) del estado de Oaxaca sobresalió la ZMO correspondiente a Valles Centrales; y en 
la "competitividad turística" (IT) las ciudades que destacaron fueron Puerto Escondido, Huatulco, y la ZMO, ubicadas en las regiones de la Costa, y Valles centrales respectivamente, todas promocionadas como "ciudades turísticas". En la gráfica 7 se observa el comportamiento en conjunto de los índices de competitividad turìstica (IT) y del desarrollo sustentable (IDS) de la RCoAx. El primero inició con un nivel bajo (0.33 en el 2000), tuvo una disminución (a 0.28 en 2004), pero en el año 2009 volvió a repuntar (0.39), hasta alcanzar un nivel medio (0.49 en el 2015). En cuanto al índice del desarrollo sustentable, en el año 2000 tenía un valor de 0.60. A partir del año 2008-2015 ha continuado disminuyendo (hasta 0.49 en el 2015), manteniendo un nivel medio, pero con tendencia a la baja. Los índices se comportan de manera inversa: uno va a la alza (IT), y el otro va a la baja (IDS).

\section{Gráfica:7}

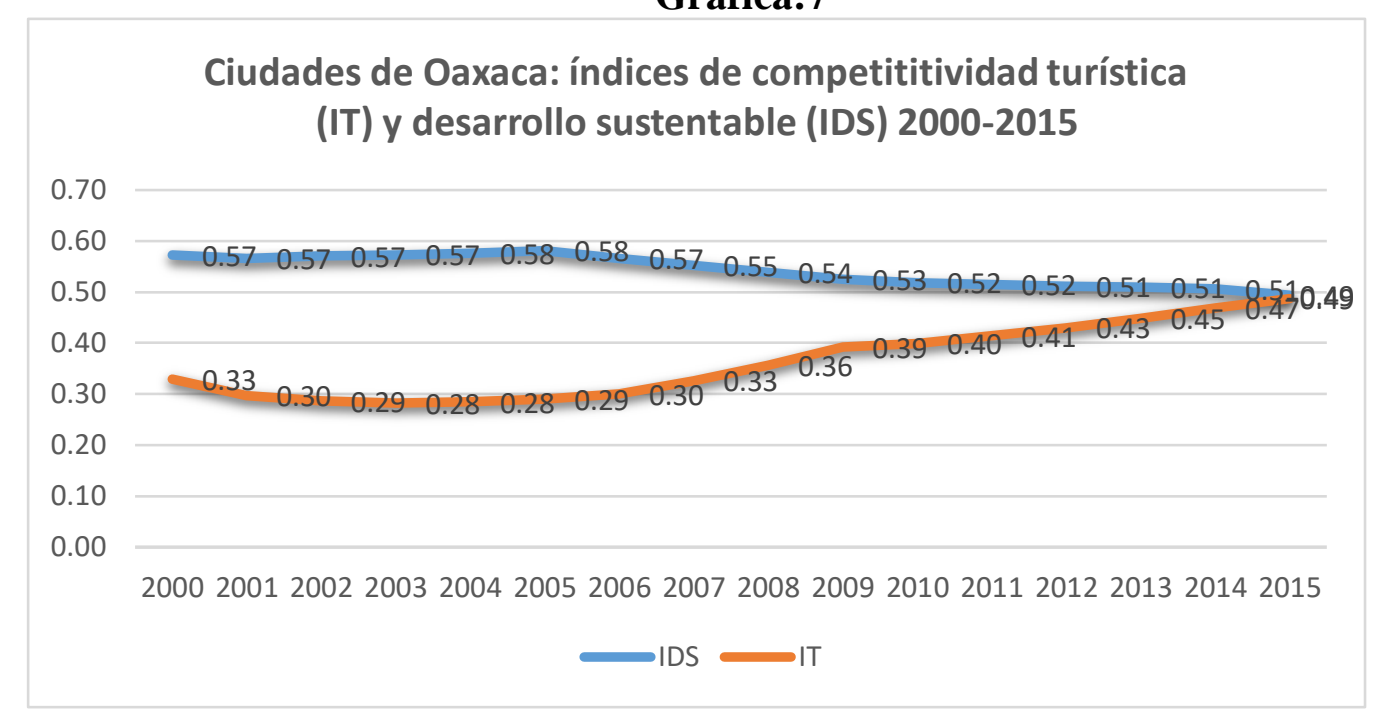

Fuente: Elaboración de los autores con datos de los censales (2000-2015, INEGI).

Para valorar la importancia y relación de estos indicadores, la hipótesis 1 propuesta es que durante 2000-2015: 1) la competitividad turística (IT) de las ciudades mantiene una influencia positiva significativa con el desarrollo sustentable (IDS) de la RCoAx; es decir, que a mayor competitividad turística mayor correlación y significancia con el desarrollo sustentable de la $\mathbf{R C o A x}$; y la hipótesis 2 propone que: a) que territorialmente, las ciudades turísticas (ZMO, Puerto y Huatulco) son las que impulsan el IDS, y las ciudades no-turísticas son la causa del debilitamiento de éste; b) que en estas ciudades, el factor ambiental (IIA) es el que impulsa sectorialmente el IDS de la RCoAx; en tanto que el factor recursos humanos (IRH) es la causa principal del debilitamiento del IDS de esta red. En los esquemas 3 y 4 se muestran los resultados empíricos obtenidos al respecto. 


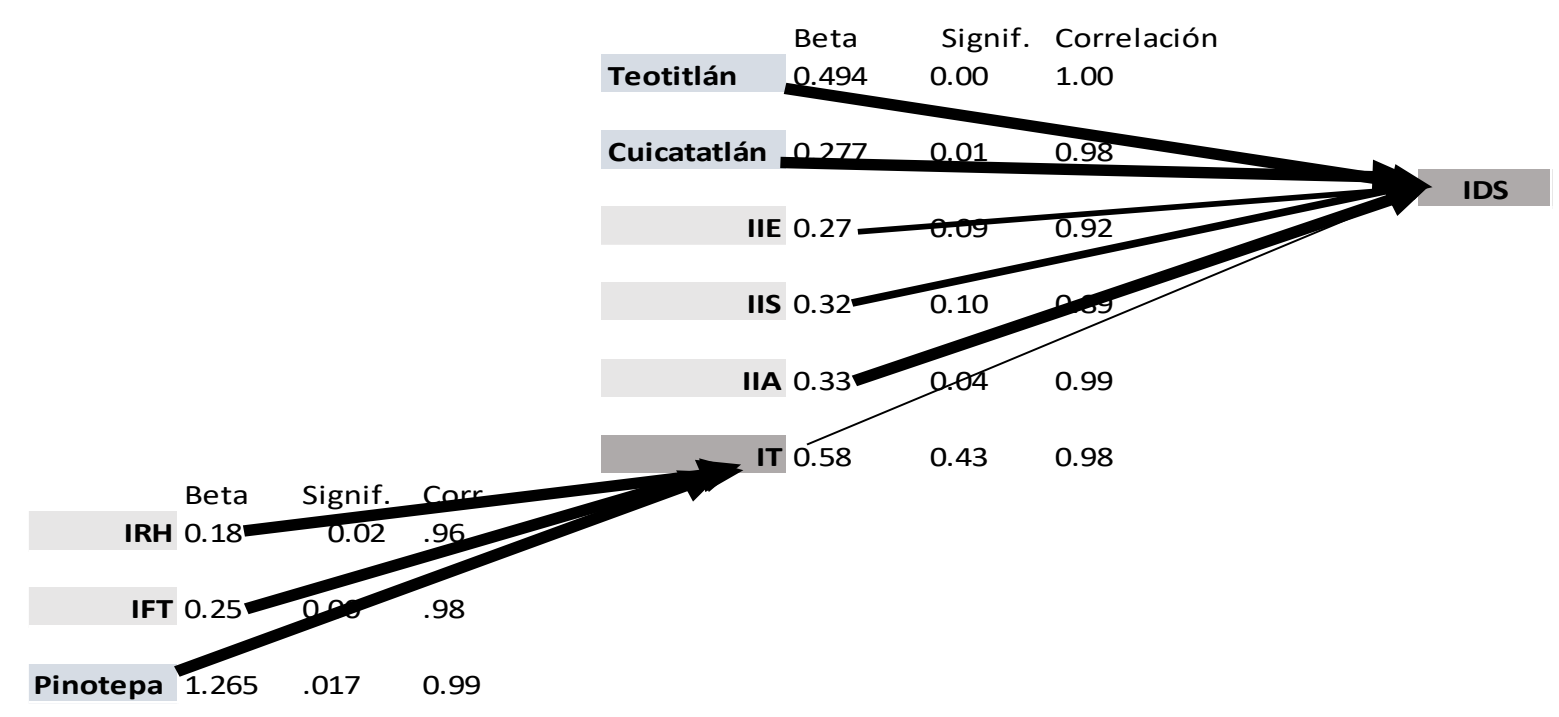

Esquema 3. Las fortalezas sectoriales y territoriales del desarrollo sustentable en la RCOAX.

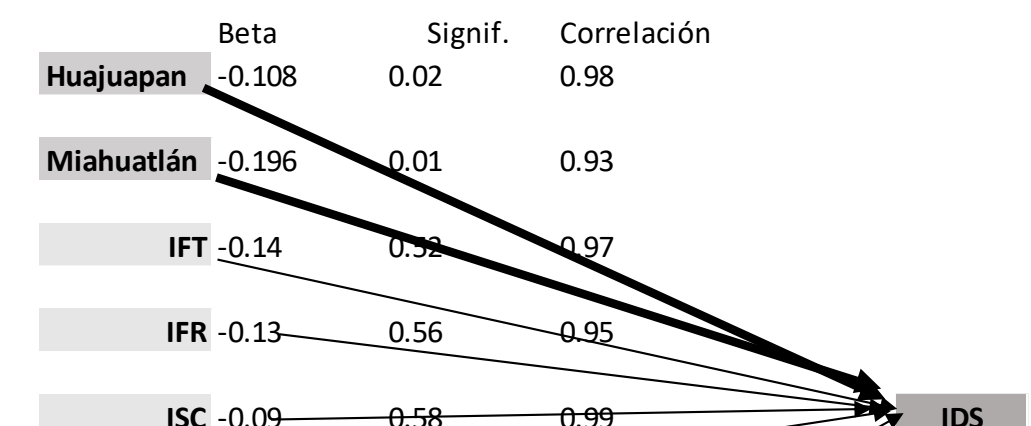

Huatulco $-.972 \quad .001$

0.93

Esquema 4. Las fortalezas sectoriales y territoriales del desarrollo sustentable en la $\boldsymbol{R} \boldsymbol{C o A x}$.

Según la información de los esquemas 3 y 4 derivados del análisis de regresión, se concluye que: 1) La competitividad turística (IT), aunque posee una alta correlación con el IDS (0.98), no posee significancia estadística (0.43) (Esquema 3 y Esquema 4). Por lo tanto, la hipótesis 1 se rechaza.

Con respecto a la hipótesis 2 , se concluye que:

b) Territorialmente las ciudades que más influyen en la relación IDS-IT son: PinotePa, que no se promociona como una "ciudad turística", influyendo directamente en el 
incremento de la competitividad turística (IT) e indirectamente en el IDS (posee significancia estadística); así como Teotitlán y Cuicatlán, ciudades también no promocionadas turísticamente, que contribuyen directamente al aumento del IDS (poseen significancia estadística). A su vez, la ciudad que más influye negativamente en la relación IDS-IT es HUAtulco, ciudad promocionada como "turística" (posee significancia estadística); y Miahuatlán y Huajuapan, ciudades no promocionadas turísticamente, son las que directamente afectan negativamente al IDS (poseen significancia estadística). Dado que territorialmente las denominadas "ciudades turísticas" no contribuyen al IDS de la $\mathbf{R C o A x , ~ l a ~ h i p o ́ t e s i s ~} 2 b$ se rechaza.

a) Los factores que más influyen en el aumento del IT, y por consiguiente en el IDS, son: el fomento turístico (IFT) como el de más peso (con una beta de 0.25 , posee significancia estadística mayor al 99\%); la capacitación de los recursos humanos (IRH) (con una beta de 0.18 , con significancia estadística del $98 \%$ ). Otros factores que influyen directamente en el IDS son el factor ambiental (IIA), el factor social (IIS), y el factor económico (IIE) (que poseen significancia estadística superior al 90\%) (Esquema 3). Comparativamente, el ISC es el factor de más peso en la reducción del IT (pero no posee significancia estadística); y otros factores que influyen directamente de manera negativa en el IDS son IFT, IFR, ISC e IRH (pero que también carecen de significancia estadística). Dado que el IIA manifiesta una influencia significativa positiva, y que aparecen más factores influyendo en el IDS de la RCoAx también de manera positiva, la hipótesis 2 a se acepta.

El análisis realizado muestra que la relación IT-IDS posee fortalezas y debilidades en la RCoax. Las fortalezas manifiestan la unión (interacción) de los factores y las ciudades. Las debilidades exponen el aislamiento de los factores y las ciudades en esta relación. La mayor fortaleza en la $\mathbf{R C o A x}$ es de carácter sectorial, no territorial, sobresaliendo el fomento turístico, la capacitación de los recursos humanos y el cuidado ambiental intencional. Territorialmente el turismo manifiesta debilidades para impulsar el mejoramiento del IDS, aunque al respeto sobresalen las pequeñas ciudades como Teotitlán, Cuicatlán y Pinotepa, lo que debe valorarse debido a que la mayoría de ellas son el lugar central de microrregiones con gran biodiversidad y bioculturalidad.

La incipiente fortaleza sectorial del turismo y el desarrollo sustentable en las ciudades de Oaxaca indica que las mismas ya poseen la ruta que les puede permitir incrementar el IDS a través del turismo: consiste en impulsar el mejoramiento de los recursos humanos y continuar incentivando acciones ambientales de las ciudades, las cuales, según la información del presente artículo, manifiestan una tendencia a la baja . Pero en general la principal debilidad de la relación IT-IDS es la falta de coordinación y acciones territoriales de las ciudades consideradas turísticas y no turísticas, debido a que actúan aisladamente.

La propuesta que deriva del análisis es que en las ciudades de Oaxaca analizadas se sugiere continuar impulsando el desarrollo del turismo sectorialmente, pero a la vez propiciar la integración territorial de sus ciudades, especialmente a través de la coordinación y planeación colegiada para impulsar un desarrollo económicamente viable, socialmente aceptable, y ambientalmente amigable en las mismas, y lograr el aprovechamiento del potencial del patrimonio turístico existente, lo que implica visualizar la promoción e integración de las ciudades consideradas no-turísticas a las rutas del turismo promocionadas, pues hoy en día están contribuyendo a elevar la calidad de vida de la población oaxaqueña de manera más destacada que las ciudades promocionadas como turísticas. 


\section{Bibliografía}

ALTÉS, C. . El turismo en América Latina y el Caribe: La experiencia del BID. Serie de informes técnicos del Departamento de Desarrollo Sostrenible.Banco Interamericano. Disponible

en http://services.iadb.org/wmsfiles/products/Publications/984876.pdf/2006.[Consulta: 30/05/201]

BIGNÉ AlCAÑIZ E, FONT AUlET X, ANDREU SIMÓ L. Marketing de Destinos Turísticos, Análisis y Estrategias de Desarrollo, ESIC EDITORIAL 2000, pp 542

COOPER C, FLETCHER J, FYALL A, GILBERT D, WANHIL S. Turismo Princípios $e$ Prácticas. Ed. Artmed, Brazil, Bookman companhia Editora Ltda a División of Armet editor SA, 2008, pp. 767

Conapo. Catálogo sistema Urbano Nacional. Obtenido de Consejo Nacional de Población. Disponible en httpp://www.conapo.gob.mx/en/CONAPO/2012.[Consulta:05/02/2016]

Conapo. Sistema urbano nacional. Obtenido de Consejo Nacional de Población. Disponible en http://www. conapo.gob.mx/es/CONAPO/catalogo_Sistema_Urbano_Nacional. 2012.[Consulta:09/02/2016]

Conapo. ( 23 de Octubre de 2014). Obtenido de Proyecciones de la población 2010-2050: http://www.conapo.gob.mx/es/CONAPO/Proyecciones.[Consulta:20/03/2016]

CROUCH G.I, RITCHIE J.R. "Tourism, Competitiveness And Social Prosperity" en Journal of Business Research 44 (pp.137-152), 1999.

DE ÁVILA BLOMBERG, A. (2008), "Diversidad cultural y diversidad biológica en Oaxaca", documento, Oaxaca, Jardín Etnobotánico. [ Links ]

ENRIQUE VELASCO, M, TORRES VALDEZ J.C, HERNÁNDEZ, HERNÁNDEZ, B.R. "El turismo y las redes territoriales en ciudades de pueblos originarios. El caso de Oaxaca, México”, Revista Turydes: Turismo y Desarrollo, n. 19 (diciembre 2015). En línea: http://www.eumed.net/rev/turydes/19/pueblos.html

INEGI. Instituto Nacional de Estadística y Geografía. 2000. Disponible en www.inegi.org.mx. .[Consulta:08/05/2016]

NEGI. Instituto Nacional de Estadística y Geografía. 2005. Disponible en www.inegi.org.mx. [Consulta:22/08/2016]

INEGI.Instituto Nacional de Estadística y Geografía. 2010. Disponible en www.inegi.org.mx. [Consulta:15/11/2016]

INEGI.Marco Geoestadístico Nacional. Productos y Servicios.2015 Localidades-Archivo Histórico-Consulta. INEGI, México. (consulta 27 de septiembre de 2015). Disponible http://www.inegi.org.mx/geo/contenidos/geoestadistica/consulta_localidades.aspx. 2015

JIMÉNEZ, N. S. La Competitividad Turística y el Desarrollo Regional Sustentable en México, 2000-2010. Oaxaca. 2013. 
ENRIQUE VELASCO, M. Ciencia regional. Principios de economía y desarrollo, Oaxaca. Oaxaca, México, Edicción :CONACYT, ITO, DGETI, Instituto Tecnológico de Oaxaca, julio, 2014, pp 329

OMT. Panorama OMT del turismo internacional. Disponible en datos y cifras: http://mkt.unwto.org/sites/all/files/docpdf/unwtohighlights10sphr.pdf. 2010. [Consulta:11/04/2016]

PNUD. Índices de Desarrollo Humano: 2000, 2005 y 2010. Cálculos de la Oficina de Investigación en Desarrollo Humano (OIDH). México: PNUD México. 2014.

SARMIENTO FAUSTO O. Diccionario de Ecología. Disponible en www.ensayistas.org/crítica/ecología/diccionario/i.tm. 2010. [Consulta:03/09/2016]

SEMARNAT. Ciudades sustentables.(consulta el 22 de octubre de 2015). Disponible en http://ccds.semarnat.gob.mx/regiones/ccnds/2002.2003.[Consulta:19/12/2016]

SECTUR. (2012). Las motivaciones de viaje, así como las formas para practicar cada uno. Disponible en http://www.google.com.mx .[Consulta:18/05/2016]

SEPÚLVEDA S., S. Metodología para estimar el nivel de desarrollosostenible de territorios, IICA, Sede Central, San José, Costa Rica, Sergio Sepúlveda, marzo, 2008, pp. 119

Sistema de Información Municipal. Gobierno del estado de Oaxaca. CIEDD Centro de Información Estadística y Documental para el Desarrollo 2014, Censos

Económicos 200, Oaxaca, México (consulta 25 de mayo de 2014). Disponible en http://www.sim.oaxaca.gob.mx/. 2014.[Consulta:08/05/2016]

JAIME, S. Competitividad Territorial: Ámbito e Indicadores de Análisis, Economia, Sociedad y Territorio, 2005, Dossier Especial. Toluca, México: El colegio Mexiquence A.C. Recuperado el 10 de Mayo de 2015 Disponible en:Shttp://www.redalyc.org/articulo.oa?id=11109906> ISSN 1405-842

MARTíNEZ, G. K., MiGUEL, V. A., LÓPEZ, V. M., PÉREZ, P. M., MORENO, A. J., MONCADA, G. M., \& OSORIO, H. M. (2018). La Vivienda en el Desarrollo Sustentable de las Pequeñas, Medianas y Grandes Ciudades de Oaxaca. Oaxaca: Biblioteca virtual de Derecho, Economía y Ciencias Sociales. Obtenido de https://www.eumed.net/libros/1727/index.html

MONCADA, M. d. (20 de Enero de 2018). La competitividad turística y el desarrollo sustentable de ciudades del estado de Oaxaca, México. Oaxaca: Instituto Técnologico de Oaxaca. 